\title{
Mechanisms of Waterlogging Tolerance in Plants: Research Progress and Prospects
}

\author{
Jiawei Pan ${ }^{1,2}$, Rahat Sharif', Xuewen $X^{1,2}$ and Xuehao Chen ${ }^{1,2 *}$ \\ ${ }^{1}$ School of Horticulture and Plant Protection, Yangzhou University, Yangzhou, China, ${ }^{2}$ Joint International Research \\ Laboratory of Agriculture and Agri-Product Safety, Yangzhou University, Yangzhou, China
}

OPEN ACCESS

Edited by:

Setsuko Komatsu,

Fukui University of Technology, Japan

Reviewed by:

Mirza Hasanuzzaman,

Sher-e-Bangla Agricultural University,

Bangladesh

Zhulong Chan,

Huazhong Agricultural University,

China

${ }^{*}$ Correspondence:

Xuehao Chen

xhchen@yzu.edu.cn

Specialty section:

This article was submitted to

Plant Abiotic Stress,

a section of the journal

Frontiers in Plant Science

Received: 09 November 2020 Accepted: 30 December 2020

Published: 10 February 2021

Citation:

Pan J, Sharif $R, X u X$ and Chen $X$ (2021) Mechanisms of Waterlogging Tolerance in Plants: Research Progress and Prospects. Front. Plant Sci. 11:627331. doi: 10.3389/fpls.2020.627331
Waterlogging is one of the main abiotic stresses suffered by plants. Inhibition of aerobic respiration during waterlogging limits energy metabolism and restricts growth and a wide range of developmental processes, from seed germination to vegetative growth and further reproductive growth. Plants respond to waterlogging stress by regulating their morphological structure, energy metabolism, endogenous hormone biosynthesis, and signaling processes. In this updated review, we systematically summarize the changes in morphological structure, photosynthesis, respiration, reactive oxygen species damage, plant hormone synthesis, and signaling cascades after plants were subjected to waterlogging stress. Finally, we propose future challenges and research directions in this field.

Keywords: waterlogging stress, morphological structure, photosynthesis, energy metabolism, plant hormones, molecular mechanism

\section{INTRODUCTION}

Plants achieve normal growth through the coordination of water absorption by the roots with transpiration from the leaves. Sufficient water is a prerequisite for normal growth of plants, but saturation of the soil water-holding capacity, or even super-saturation, easily leads to waterlogging stress. The inhibition of root respiration and accumulation of toxic substances during waterlogging stress have adverse effects not only on vegetative growth, but also on reproductive growth, eventually leading to yield loss or even complete harvest failure (Hirabayashi et al., 2013; Xu et al., 2014; Herzog et al., 2016; Tian et al., 2019; Ding et al., 2020; Zhou et al., 2020). Therefore, in the context of global warming, with predictions of more frequent and/or heavy rainfall and frequent flood disasters, there is a pressing need to study plant waterlogging tolerance and its mechanisms in order to maintain successful agriculture and promote effective adaptations to the changing climate (Bailey-Serres et al., 2012; Nishiuchi et al., 2012; Mondal et al., 2020).

During waterlogging, leaf stomata close, whereas chlorophyll degradation, leaf senescence, and yellowing reduce the ability of leaves to capture light and ultimately lead to a decline in photosynthetic rate (Kuai et al., 2014; Yan et al., 2018). Waterlogging removes air from soil pores, resulting in blocked gas exchange between soil and atmosphere; at the same time, the oxygen diffusion rate in water is only $1 / 10,000$ of that in air. Consequently, oxygen availability in waterlogged soil is greatly restricted, resulting in suppressed roots respiration, decreased root activity, and energy shortage (van Veen et al., 2014). Plants can temporarily maintain energy production to some extent during hypoxia caused by waterlogging, via glycolysis and ethanol fermentation. However, prolonged duration of waterlogging and anaerobic respiration ultimately 
leads to the accumulation of toxic metabolites such as lactic acid, ethanol, and aldehydes, combined with an increases in reactive oxygen species (ROS), notably hydrogen peroxide, thus eventually leading to cell death and plant senescence (Xu et al., 2014; Zhang P. et al., 2017). Hindered gaseous exchange can also lead to rapid accumulation or degradation of plant hormones and further affect plant waterlogging tolerance (Hattori et al., 2009; Kuroha et al., 2018). Although most plants perform poorly when waterlogged, they can adapt to the damage caused by such environmental stress through various strategies (Fukao et al., 2006; Xu et al., 2016; Doupis et al., 2017; Yin et al., 2019).

The flooding stress, which further causes the submergence; hypoxia; and waterlogging stress are the main limiting factors of crop productivity. Flooding imposes submergence and ultimately raises the ground water table, which creates a hypoxic condition in the rhizosphere. The hypoxic condition in the rhizosphere restricts the oxygen uptake by causing an anaerobic environment, which further leads to plant death (Fukao et al., 2019), Therefore, the flooding, submergence, and waterlogging stress are interconnected and affect the plant in nearly similar fashion (Fukao et al., 2019).

In this updated review, we summarize the progress of research on plant adaptations to waterlogging stress with a focus on six aspects: morphological and anatomical adaptations, photosynthesis, respiration, ROS injury, plant hormone biosynthesis and signaling cascades, and genetic engineering in enhancing tolerance of plant against waterlogging stress (Figure 1). Finally, the future challenges and research direction in this field are discussed, aiming to provide a source of reference and recommendations for further research on plant waterlogging resistance.

\section{MORPHOLOGICAL AND ANATOMICAL ADAPTATION}

Most plants are sensitive to waterlogging, as the diffusion rates of $\mathrm{O}_{2}$ and $\mathrm{CO}_{2}$ in roots and stems of plants decrease significantly during waterlogging, and photosynthesis and respiration are significantly inhibited. However, various morphological changes occur in some plants and can relieve root respiratory depression and damage caused by disrupted energy metabolism under waterlogging. Morphological changes are mainly manifested as the formation of adventitious roots (ARs) or other aeration tissues, rapid elongation of apical meristematic tissue, barriers to radial oxygen loss (ROL), and the formation of air films in the upper cuticle (Hattori et al., 2009; Pedersen et al., 2009; Yamauchi et al., 2017; Qi et al., 2019).

Formation of ARs is a typical adaptive change in morphology (Steffens and Rasmussen, 2016). During extended waterlogging, ARs develop in the internodes on the hypocotyl or at the base of the stem, where they promote the exchange of gases and the absorption of water and nutrients. To a certain extent, AR formation can replace the primary roots that die because of hypoxia stress, maintaining metabolic cycles, and enabling normal growth and development (Xu et al., 2016; Eysholdt-Derzsó and Sauter, 2019). The newly formed ARs contain more aerenchyma than the primary roots, which augment both $\mathrm{O}_{2}$ uptake and diffusion ability (Visser and Voesenek, 2005).

Programmed cell death and degradation occur in cortical cells of plant root under hypoxia, producing tissue cavities and leading to aerenchyma formation. Aerenchyma not only can transport $\mathrm{O}_{2}$ from non-waterlogged tissue to the root system, but also discharge $\mathrm{CO}_{2}$ and toxic volatile substances from waterlogged tissue. Therefore, aerenchyma provides the possibility of gas exchange within plants and is vital for maintaining the normal physiological metabolism in the cells of waterlogged roots (Drew et al., 2000; Evans, 2004; Yamauchi et al., 2013).

Radial oxygen loss refers to the fact that $\mathrm{O}_{2}$ can be consumed by respiration during the longitudinal transport of $\mathrm{O}_{2}$ along the aerenchyma to the root tip and can also be lost by lateral leakage into the intercellular spaces of the rhizosphere (Yamauchi et al., 2018). Plants are able to produce a barrier to ROL, thereby reducing the loss of $\mathrm{O}_{2}$ to the intercellular spaces of the rhizosphere and $\mathrm{O}_{2}$ diversion between and around the root tip (Pedersen et al., 2020). Abiko and Miyasaka (2020) used methylene blue to stain the ARs of taro [Colocasia esculenta (L.) Schott] after 8 days of waterlogging and found that the root tips turned blue, whereas no blue areas appeared in the middle sections of the roots. This indicated that $\mathrm{O}_{2}$ leakage was detected only near the root tip along the intercellular spaces of the rhizosphere, as the ROL barrier was formed in the middle of the root and prevented lateral losses (Shiono et al., 2011). The formation of the ROL barrier inhibited the release of $\mathrm{O}_{2}$ in the primordia of aerenchyma in rice (Oryza sativa) after $12 \mathrm{~h}$ of waterlogging (Shiono et al., 2011). Moreover, deepwater rice cultivars form a tighter ROL barrier under low oxygen conditions than upland rice (Colmer, 2002).

The rapid elongation of plant apical meristems is another adaptation of plants to waterlogging. The rapid elongation of tender stems and internodes facilitates escape from the anoxic environment and contact with the air as soon as possible, thereby enabling normal respiration (Kuroha et al., 2018). This response is known as low oxygen escape syndrome (LOES). Internodes of deepwater rice cultivars elongate rapidly: waterlogging induces accumulation of ethylene (ET) and promotes synthesis of gibberellins (GAs) (largely $\mathrm{GA}_{4}$ ), thus promoting internode elongation (Kuroha et al., 2018) (see also Waterlogging stress mediated by plant hormones).

As an adaptation to waterlogging, some plants maintain a gas film on the leaf surface when submerged (Winkel et al., 2016; Kurokawa et al., 2018). The gas film promotes the entry of $\mathrm{O}_{2}$ in darkness and $\mathrm{CO}_{2}$ when in light, thus contributing to the maintenance of aerobic respiration and photosynthesis. After artificial removal of the gas film in waterlogged rice, the underwater net photosynthetic rate was found to be only $20 \%$ of that with the gas film in place (Pedersen et al., 2009).

\section{PHOTOSYNTHETIC ADAPTATION}

During waterlogging, stomatal conductance of leaves decreases, stomatal resistance increases, stomatal closure increases, and 


\section{waterlogging stress}
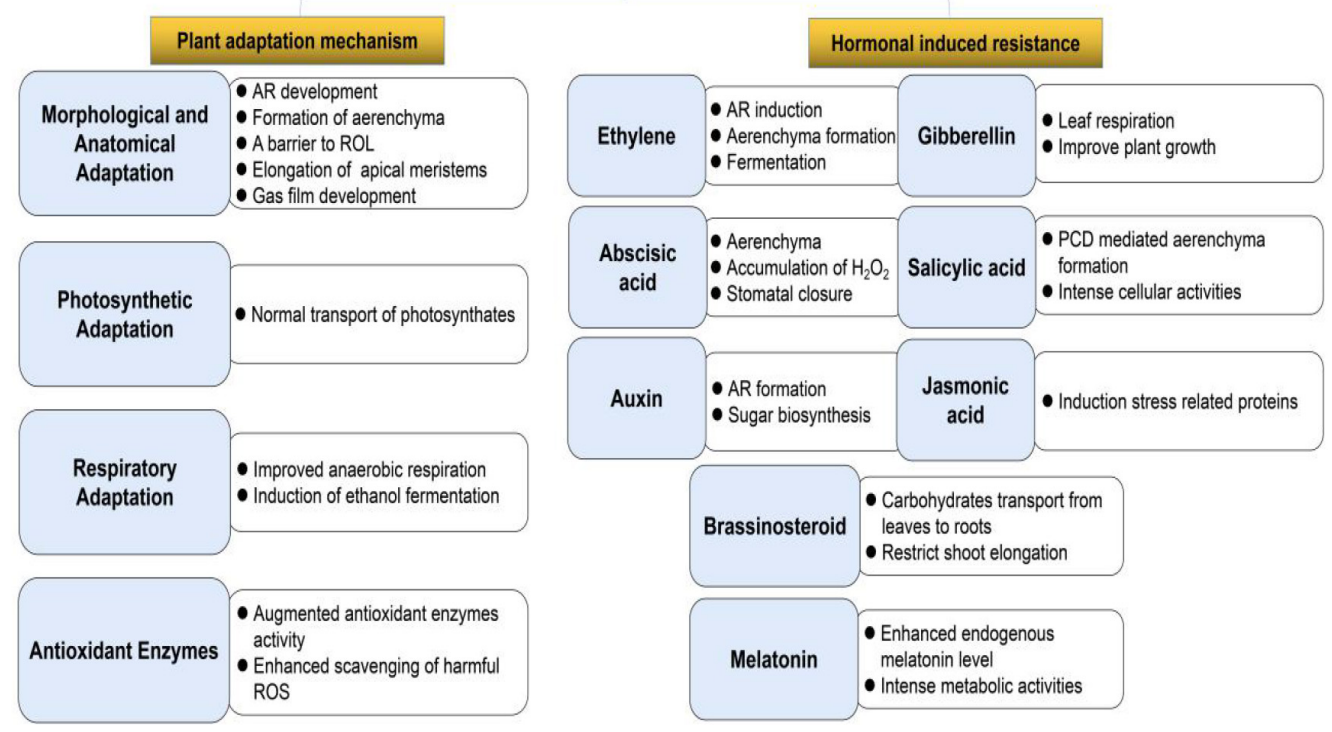

FIGURE 1 | Schematic representation of plant response to waterlogging stress and hormonal effects resistance in plants.

absorption of $\mathrm{CO}_{2}$ is reduced (Li et al., 2010). However, plants need $\mathrm{CO}_{2}$ and light for photosynthesis to maintain growth and development. Under prolonged waterlogging condition, the enzyme activities related to photosynthesis were inhibited; the chlorophyll synthesis ability of leaves decreased, leading to leaf senescence, yellowing, and peeling; the formation of new leaves was blocked, and then the photosynthetic rate decreased, finally leading to death of the plants (Voesenek et al., 2006; Wu and Yang, 2016).

Photosynthetic pigments are the material basis of plant photosynthesis, and the change of pigment content and composition directly affects the photosynthetic rate. Anee et al. (2019) conducted waterlogging experiments on sesame (Sesamum indicum L.) seeds for $2,4,6$, and 8 days to explore the changes in physiological and biochemical characteristics with time under waterlogging. The content of the photosynthetic pigments, chlorophyll $\mathrm{A}, \mathrm{B}$ chlorophyll $\mathrm{A}+\mathrm{B}$, and carotenoids, was significantly lower in waterlogged seeds than in the unwaterlogged control; as the content of photosynthetic pigments decreased, the photosynthetic capacity also decreased.

The enzyme rubisco catalyzes the first step of both the photosynthetic carbon cycle and photorespiration and plays a key role in regulating the photosynthetic rate. After $24 \mathrm{~h}$ upon waterlogging stress, the expression of rubisco and rubisco activase genes in cotton (Gossypium hirsutum L.) leaves was downregulated; a reduction in net photosynthetic rate of cotton was mainly caused by lower rubisco activity. Sucrose and starch are the main products of photosynthesis in most plants. Sucrose is the main transport carbohydrate from source to sink, a process that is very sensitive to waterlogging. The decreased photosynthetic rate, sucrose conversion rate, and initial rubisco activity directly reduced the boll weight of waterlogged cotton. The enzyme sucrose synthase is central to the metabolic breakdown of sucrose required for cellulose biosynthesis; increased gene expression and enzyme activity of sucrose synthase during waterlogging were associated with prolonging the period of rapid accumulation of seed fiber weight, tending to reduce the phenomenon of boll weight decline caused by waterlogging (Kuai et al., 2014).

\section{RESPIRATORY ADAPTATION}

The generation of energy is crucial for plant growth and development. The lack of energy caused by hypoxia and consequent inhibition of root respiration are some of the most serious problems faced by plants under waterlogging (Loreti et al., 2016). In cultivated soil, the concentration of dissolved oxygen in water is generally approximately $0.23 \mathrm{~mol} / \mathrm{m}^{3}$, whereas in waterlogged conditions, the concentration of dissolved oxygen in water is less than $0.05 \mathrm{mmol} / \mathrm{m}^{3}$. The diffusion rate of $\mathrm{O}_{2}$ in waterlogged soil is only $1 / 10,000$ of that in the air. $\mathrm{O}_{2}$ is the electron acceptor at the end of the mitochondrial electron transport chain. Decreased $\mathrm{O}_{2}$ availability rapidly inhibits the production of adenosine triphosphate (ATP) by interfering with the electron transport chain, leading to inhibition of mitochondrial respiration (Bailey-Serres and Voesenek, 2008; Limami et al., 2014). Plants need to obtain the necessary energy supply through glycolysis and ethanol fermentation so as to cope with the energy shortage caused by waterlogging stress (Baxter-Burrell et al., 2002). However, 1 mol glucose can produce 36 to $38 \mathrm{~mol}$ ATP through the tricarboxylic acid cycle, whereas only $2 \mathrm{~mol}$ ATP can be obtained through glycolysis and ethanol fermentation. Therefore, plants need to accelerate glycolysis and ethanol fermentation in order to obtain the necessary amounts of ATP needed to sustain life. 
Pyruvate accumulated from glycolysis can be used for anaerobic fermentation. Pyruvate fermentation produces energy in two different ways, producing lactic acid either via lactate dehydrogenase (LDH) or via pyruvate decarboxylase (PDC) turning pyruvate into acetaldehyde, which is then reduced to ethanol by alcohol dehydrogenase (ADH) (Zabalza et al., 2009; Caruso et al., 2012; Borella et al., 2019). ADH and PDC play key roles in the ethanol fermentation pathway, and their activity is usually considered as one of the important indexes reflecting the tolerance of plants to waterlogging. Waterlogging-tolerant plants can improve the ethanol fermentation rate by regulating the expression of $A D H, P D C$, and other related enzyme genes, which can temporarily provide energy for the growth of plants under waterlogging (Zhang P. et al., 2017). Therefore, fermentation is a necessary process of energy metabolism under waterlogging, as shown by the up-regulated expression of anaerobic metabolism genes such as PDCs and ADHs in cucumber, cotton, and soybean (Komatsu et al., 2011; Xu et al., 2014; Zhang et al., 2015). The seed germination ability of $G m A D H 2$-transgenic soybeans was enhanced under waterlogging, and the GmADH2 gene was induced during glycolysis and ethanol fermentation (Tougou et al., 2012). The overexpression of kiwifruit PDC1 gene in transgenic Arabidopsis enhanced waterlogging tolerance (Zhang J.Y. et al., 2016). These results indicate that $P D C$ and $A D H$ genes play key roles in plant waterlogging tolerance.

Lactate dehydrogenase also participates in the waterlogging stress response, alongside $\mathrm{PDC}$ and $\mathrm{ADH}$. Overexpression of $L D H$ significantly enhanced the PDC activity and hypoxia resistance of Arabidopsis, whereas LDH loss of function mutant $l d h$ showed the opposite phenotype (Dolferus et al., 2008). Therefore, lactic acid fermentation is an important pathway in response to waterlogging stress in some plants. The transcript abundances of the ethanol dehydrogenase genes ADH1-1, ADH1-2, ADH1-3, and PDC genes PDC1 and PDC2 were down-regulated in Petunia plants in which an ETresponsive element-binding factor PhERF2 was silenced, whereas they were up-regulated in PhERF2-overexpressing plants. In contrast, the expression of $\mathrm{LDH}$ gene $L D H$ was up-regulated in PhERF2-silenced lines and down-regulated in PhERF2overexpressing lines. This result suggests that the main pathway for $\mathrm{NAD}^{+}$regeneration in PhERF-overexpressing plants is ethanol fermentation, whereas $P h E R F 2$-silenced plants might rely on lactic acid fermentation in response to waterlogging stress (Yin et al., 2019).

Although the energy generated via glycolysis and ethanol fermentation can temporarily alleviate the energy deficiency caused by the inhibition of respiration in roots, the accumulation of toxic substances such as lactic acid, alcohols, aldehydes, and other anaerobic metabolites eventually leads to plant death as the time of waterlogging is prolonged (Tamang et al., 2014).

\section{DAMAGE BY REACTIVE OXYGEN SPECIES}

Reactive oxygen species are a normal product of plant cell metabolism. Insufficient $\mathrm{O}_{2}$ will also lead to increases in intracellular ROS under waterlogging stress (Bailey-Serres and Chang, 2005; Pucciariello et al., 2012). For example, superoxide radicals $\left(\cdot \mathrm{O}_{2}\right)$, hydroxyl radicals $(\cdot \mathrm{OH})$, and hydrogen peroxide $\left(\mathrm{H}_{2} \mathrm{O}_{2}\right)$ have strong oxidizing activity that can lead to lipid peroxidation and delipidation of leaf membranes, oxidative damage to proteins, oxidative damage to DNA, and severe damage to cell membranes and organelles (Sharma et al., 2012; Baxter et al., 2014).

Although excessive ROS are harmful to plant cells, ROS can also act as signaling molecules in plant cells under stress. Plant NADPH oxidase is a key enzyme in the production of ROS and plays a vital role in ROS-mediated signal transduction. The expression of NADPH oxidase-related gene Atrboh $D$, a gene associated with ROS production, is induced by waterlogging and positively regulates the production of $\mathrm{H}_{2} \mathrm{O}_{2}$ and the increase of ADH1 gene expression in Arabidopsis. Therefore, this signal improves the capacity for ethanol fermentation and increases the survival rate of plants under waterlogging (Sun et al., 2018). Analysis of the atrboh $d$ mutant by Yang and Hong (2015) showed that AtRboh $D$ is involved in the primary hypoxia signaling pathway and can regulate the transcription of ET synthesis gene ACC synthetase7/8 (ACS7/8), as well as the regulation of hypoxia-induced downstream genes such as ERF73/HRE1 and $A D H 1$ and the expression of genes encoding peroxidase and cytoplasmic P450. Subsequently, Liu et al. (2017) analyzed the single mutant atrboh $d$ and atrboh $f$ and the doublemutant atrbohd/f. Both Atrboh $D$ and Atrboh $F$ play a role in hypoxia signal through the production of ROS, promoting the increase of $\mathrm{Ca}^{2+}$ and mediating hypoxia-induced expression of downstream genes, such as $A D H 1, P D C 1, E R F 73, M Y B 2, L D H$, SUS1, SUS4, HsfA2, and HSP18.2, thus improving the tolerance of Arabidopsis to hypoxia stress. These findings provide new insights into the adaptation mechanism of Rboh gene regulation under waterlogging stress in plants.

$\mathrm{H}_{2} \mathrm{O}_{2}$ is an essential signaling molecule involved in ETinduced epidermal cell death. The formation of aerenchyma in rice stems is controlled by $\mathrm{H}_{2} \mathrm{O}_{2}$, indicating that ROS play a key role in regulating various cell death processes in rice (Steffens et al., 2011). $\mathrm{H}_{2} \mathrm{O}_{2}$ plays a role in primary hypoxia signaling by regulating ET signal transduction and modulating the transcription of downstream hypoxia-induced genes such as ERF73/HRE1 and ADH1 in Arabidopsis (Yang, 2014). This signal promoted the capacity for ethanol fermentation, temporarily alleviated the energy shortage, and improved the adaptability of the plants to waterlogging.

Under waterlogging stress, plants can rely on antioxidant enzyme systems and other active antioxidants to maintain the dynamic balance of ROS, thus reducing the extent of oxidative damage (Zhang et al., 2007; Bin et al., 2010; Doupis et al., 2017; Hasanuzzaman et al., 2020). Waterlogging treatment resulted in increased activities of catalase (CAT), ascorbate peroxidase (APX), and superoxide dismutase (SOD), as well as polyphenol oxidase. Furthermore, the enzyme activity of waterlogging-resistant lines was significantly higher than that of waterlogging-sensitive lines (Bansal and Srivastava, 2012). Li (2007) took two cucumber varieties with significantly different waterlogging tolerance as test materials and found that the 
activities of SOD, POD, and CAT, as well as chlorophyll content, soluble sugar content, and CAT content of waterlogging-sensitive lines, decreased rapidly; there was no significant difference between waterlogging-resistant lines in the early stress (13 days) treatment and the control. After 3 days, they all decreased rapidly, but the extent of the decrease was smaller than that of waterlogging-sensitive lines. Several genotypes of maize were subjected to waterlogging stress. Genotypes withstanding the waterlogging stress displayed higher SOD, POD, and CAT activities (Li et al., 2018). Similarly, induced SOD and CAT activities were observed in the Sorghum bicolor waterlogging-resistant lines JN01 and JZ31 (Zhang R. et al., 2019). Waterlogging stress was given to barley-tolerant and sensitive genotypes for 21 days to evaluate the antioxidant response (Luan et al., 2018). The study revealed that SOD, POD, and CAT activities were increased in both the tolerant and sensitive genotypes (Luan et al., 2018). It could be presumed that enhanced antioxidant activities under waterlogging stress can increase the tolerance of plant for a certain amount of time. However, extended waterlogging stress leads to the dysfunctioning of mitochondria, which is the key regulator of antioxidant enzyme activities (Sharif et al., 2018).

The activity of APX in eggplant roots under waterlogging was higher than that of other antioxidant enzymes, and the activity of APX was higher than that of tomato. Consequently, eggplant had higher adaptation ability to waterlogging (Lin et al., 2004). Lee et al. (2014) conducted waterlogging experiments on rapeseed seedlings and found that a CAT-encoding gene was downregulated, whereas $\mathrm{SOD}$ and $\mathrm{POD}$ genes were up-regulated. CAT might be involved in controlling $\mathrm{H}_{2} \mathrm{O}_{2}$ content by converting $\mathrm{H}_{2} \mathrm{O}_{2}$ into $\mathrm{O}_{2}$. The down-regulation of this gene would then increase the content of $\mathrm{H}_{2} \mathrm{O}_{2}$ in the leaves of rape seedlings and eventually damage the photosynthetic organs, leading to premature aging.

The application of exogenous regulatory substances is one of the main ways to improve the antioxidant capacity of waterlogged crops (An et al., 2016). For example, application of $\gamma$-aminobutyric acid can increase the photosynthetic rate and chlorophyll content by triggering the activity of antioxidant enzymes (SOD, POD, CAT, GR, APX), suppress the malondialdehyde (MDA) contents and $\mathrm{H}_{2} \mathrm{O}_{2}$, and thus improve the waterlogging tolerance of maize (Zea mays L.) (Salah et al., 2019). The $\mathrm{H}_{2} \mathrm{O}_{2}$ application at low concentrations can also induce plant tolerance to stress (Hossain et al., 2015). In line with that, Andrade et al. (2018) pretreated soybean seeds with $70 \mathrm{mM} \mathrm{H} \mathrm{H}_{2} \mathrm{O}_{2}$ solution for $24 \mathrm{~h}$ and then subjected the seedlings to waterlogging for 32 days. The obtained results revealed that $\mathrm{H}_{2} \mathrm{O}_{2}$ pretreatment promoted the antioxidant system activity and net photosynthetic rate under waterlogging and at the same time reduced the production of ROS and the degree of cell membrane damage, conferring enhanced waterlogging tolerance of soybean. The above results indicate that the ROS-scavenging ability of plants can be enhanced by increasing in active antioxidant substances, and the waterlogging-resistant lines maintained high antioxidant enzyme activities that enabled them to resist oxidative damage caused by waterlogging.

\section{WATERLOGGING STRESS MEDIATED BY PLANT HORMONES}

Endogenous plant hormones are closely involved in the regulation of the entire life process of plants, and the balance of various hormones is the basis to ensure normal physiological metabolism, growth, and development of plants (Bartoli et al., 2013; Miransari and Smith, 2014; Wang X. et al., 2020). The plant changes the balance of synthesis and transport of plant hormones and regulates the response to waterlogging via complex signaling. Plant hormones, as important endogenous signals, play a central role in the mechanism of waterlogging tolerance (Benschop et al., 2006; Wu et al., 2019; Yamauchi et al., 2020). Some selected recent studies on phytohormones and plant growth regulatormediated waterlogging tolerance in plants are presented in Table 1. A model drawing together the interactions of the various signals, growth regulators, genes, and processes involved in the response of plants to waterlogging is summarized in Figure 2.

\section{Ethylene}

Ethylene is a gaseous hormone in plants, and its diffusion rate is extremely low in water. The rapid accumulation of ET is an important way in which plants respond to waterlogging (Alpuerto et al., 2016; Hartman et al., 2019a,b).

1-Aminocyclopropane-1-carboxylic acid (ACC), the direct precursor in the biosynthesis of $\mathrm{ET}$, is produced in large quantities under the catalysis of ACC synthase (ACS), and the process can occur under hypoxic conditions. ACC is converted to ET under the catalysis of ACC oxidase (ACO), but the process needs the participation of $\mathrm{O}_{2}$; thus, ACC needs to be continuously transferred from the hypoxic environment of the root system to the lower region of the plant's aerobic part where the oxidation reaction can take place, finally producing ET. Rauf et al. (2013) found that waterlogging directly or indirectly activates the expression of ACO5 and ACS genes in Arabidopsis and increases ET biosynthesis.

ET synthesis and perception are necessary for AR formation. Waterlogging treatment was carried out on 4-week-old tomato (Solanum lycopersicum) seedlings, and $500 \mu \mathrm{M}$ aminoethoxyvinylglycine (AVG), which inhibits ET biosynthesis, was sprayed on the above-ground parts daily. After $72 \mathrm{~h}$ of waterlogging, AR primordia became visible in the stem base of waterlogged plants that had not been treated with AVG, and these primordia elongated and generated a large number of ARs within 7 days. The number of ARs in tomato plants treated with the inhibitor AVG was significantly lower than in untreated plants (Vidoz et al., 2010). Qi et al. (2019) found that treating cucumber seedlings with $1 \mathrm{mg} / \mathrm{L} 1$-methylcyclopropene (1-MCP, an ET receptor inhibitor) before waterlogging inhibited the formation of ARs, whereas exogenous $10 \mu \mathrm{M}$ ACC promoted the formation of ARs under waterlogging. Kim et al. (2018) not only significantly induced the occurrence of ARs on soybean plants but also increased the root surface area by exogenous application of 50,100 , or $200 \mu \mathrm{M}$ ethephon, a synthetic plant growth regulator that produces ET when metabolized. 
TABLE 1 | Recent studies on phytohormones and plant growth regulator mediated waterlogging tolerance in plants.

\begin{tabular}{|c|c|c|c|c|}
\hline Plant/crop species & $\begin{array}{l}\text { Exogenous } \\
\text { phytohormones } \\
\text { or plant growth } \\
\text { regulator } \\
\text { concentration } \\
\text { applied }\end{array}$ & Experimental conditions & Functional response & References \\
\hline Solanum lycopersicum & $500 \mu \mathrm{M}$ AVG & $\begin{array}{l}\text { Four-week-old plants were flooded, and the } \\
\text { aerial part was sprayed with } 500 \mu \mathrm{M} \text { AVG } 12 \mathrm{~h} \\
\text { before the start of flooding }\end{array}$ & AVG inhibited the AR formation & Vidoz et al., 2010 \\
\hline Cucumis sativus & $\begin{array}{l}1 \mathrm{mg} / \mathrm{L} 1-\mathrm{MCP} \text { or } \\
10 \mu \mathrm{M} \text { ACC }\end{array}$ & $\begin{array}{l}\text { 13-day-old seedlings were pretreated with } \\
\text { 1-MCP for } 24 \mathrm{~h} \text {; 14-day-old seedlings were } \\
\text { subjected to waterlogging up to } 2 \mathrm{~cm} \text { above } \\
\text { the surface of the substrate }\end{array}$ & $\begin{array}{l}\text { Enhanced AR formation and } \\
\text { recovered plant growth under } \\
\text { waterlogging }\end{array}$ & Qi et al., 2019 \\
\hline Glycine max & $\begin{array}{l}50,100 \text {, or } 200 \mu \mathrm{M} \\
\text { ethephon }\end{array}$ & $\begin{array}{l}\text { During the } V 2 \text { stage and the water level was } \\
\text { maintained at } 10-15 \mathrm{~cm} \text { above the soil surface } \\
\text { for } 10 \text { days }\end{array}$ & $\begin{array}{l}\text { Induced the occurrence of ARs } \\
\text { and increased the root surface } \\
\text { area }\end{array}$ & Kim et al., 2018 \\
\hline G. $\max$ & $1 \mu \mathrm{M}$ ABA & $\begin{array}{l}\text { Primary leaves had fully expanded (10-11 days } \\
\text { after sowing), and the level of water or ABA } \\
\text { solution was maintained at } 3 \mathrm{~cm} \text { above the } \\
\text { sand surface }\end{array}$ & $\begin{array}{l}\text { Inhibited the cellular } \\
\text { development of aerenchyma }\end{array}$ & Shimamura et al., 2014 \\
\hline Solanum dulcamara & $\begin{array}{l}100 \mu \mathrm{M} \text { and } 1 \mathrm{mM} \\
\mathrm{ABA}\end{array}$ & $\begin{array}{l}\text { 10- to } 12 \text {-week-old plants were submerged up } \\
\text { to } 15 \mathrm{~cm} \text { above the soil in glass containers }\end{array}$ & $\begin{array}{l}\text { ABA arrested the AR } \\
\text { development resulting in } \\
\text { increased sensitivity }\end{array}$ & Dawood et al., 2016 \\
\hline G. $\max$ & $\begin{array}{l}5,10, \text { and } 50 \mu \mathrm{M} \\
\mathrm{ABA}\end{array}$ & $\begin{array}{l}\text { Two-day-old plants were flooded, and at } 4 \mathrm{~cm} \\
\text { of water above the quartz sand surface }\end{array}$ & $\begin{array}{l}\text { Improved soybean survival } \\
\text { compared with waterlogging } \\
\text { treatment alone }\end{array}$ & Komatsu et al., 2013 \\
\hline S. Iycopersicum & $1 \mathrm{mM}$ NPA & $\begin{array}{l}\text { Four-week-old plants were flooded up to the } \\
\text { first node above the cotyledons }\end{array}$ & $\begin{array}{l}\text { Inhibited AR growth after } \\
\text { flooding. }\end{array}$ & Vidoz et al., 2010 \\
\hline C. sativus & $\begin{array}{l}10 \mathrm{mg} / \mathrm{L} \text { NAA or } \\
10 \mu \mathrm{M} \text { NPA }\end{array}$ & $\begin{array}{l}\text { 3- - week-stage seedlings water levels were } \\
\text { raised } 2 \mathrm{~cm} \text { above the soil surface for } 7 \text { days }\end{array}$ & $\begin{array}{l}\text { NPA compromised the of AR } \\
\text { growth }\end{array}$ & Qi et al., 2020 \\
\hline G. $\max$ & $50 \mu \mathrm{M} J \mathrm{~A}$ & $\begin{array}{l}\text { Seedlings were transferred to glass tube and } \\
\text { covered it with plastic cap for waterlogging } \\
\text { stress }\end{array}$ & $\begin{array}{l}\text { Promoted plant growth under } \\
\text { waterlogging by inducing } \\
\text { stress-related proteins }\end{array}$ & Kamal and Komatsu, 2016 \\
\hline C. sativus & $2.1 \mathrm{nM}$ EBR & $\begin{array}{l}\text { Waterlogging stress along EBR application was } \\
\text { given to plants for } 7 \text { days consecutively before } \\
\text { collecting samples }\end{array}$ & $\begin{array}{l}\text { Increased the ethylene and } \\
\text { production and homeostasis } \\
\text { under waterlogging stress in } \\
\text { plant roots }\end{array}$ & Ma and Guo, 2014 \\
\hline Malus baccata & $\begin{array}{l}50,100,200,400 \\
\text { and } 600 \mu \mathrm{M} \mathrm{MT}\end{array}$ & $\begin{array}{l}\text { After the seedlings developed to have four } \\
\text { leaves, treated with MT by spraying or irrigation }\end{array}$ & $\begin{array}{l}\text { Plant possessed better aerobic } \\
\text { respiration to avoid } \\
\text { waterlogging-induced damage }\end{array}$ & Zheng et al., 2017 \\
\hline Medicago sativa & $100 \mu \mathrm{M} \mathrm{MT}$ & $\begin{array}{l}\text { Foliar spray of MT was performed } 1 \text { day after } \\
\text { waterlogging stress. Six- to seven-leaf stages } \\
\text { were exposed to waterlogging by maintaining } \\
1 \mathrm{~cm} \text { above the soil surface and last for } 10 \text { days }\end{array}$ & $\begin{array}{l}\text { Improved the production of } \\
\text { endogenous melatonin and } \\
\text { production of AR }\end{array}$ & Zhang R. et al., 2019 \\
\hline
\end{tabular}

The production of endogenous ET is closely related to the development of aerenchyma cells (Kreuzwieser and Rennenberg, 2014; Mignolli et al., 2020). The expression of ACS1 and ACO5 is induced in rice root aerenchyma under hypoxia and promotes ET synthesis. At the same time, ET induces cortical cell death, mediated by ROS, leading to aerenchyma formation (Yamauchi et al., 2017). ET accumulates in roots under waterlogging as its biosynthesis continues and the diffusion rate in water is low. ET stimulates programmed cell death that occurs during the formation of lysogenic aerenchyma (Sasidharan and Voesenek, 2015). The accumulation of ET triggers the formation of lysosomal aerenchyma in maize (Yamauchi et al., 2016), rice (Yamauchi et al., 2017), and wheat (Yamauchi et al., 2014).
ET response factor $(E R F)$ is an important transcription factor involved in plant responses to several different biotic and abiotic stresses. The ERF family genes specifically induce genes containing AGCCGCC elements and DRE/CRT cis-elements, activating or inhibiting the expression of downstream functional genes, and thereby mediating plant tolerance to various stresses (Yin et al., 2019). ERF transcription factors are regulated by ET, and exogenous ET significantly promotes ERF transcription in Arabidopsis and soybean (Hess et al., 2011; Tamang et al., 2014). ET regulates the response of Arabidopsis to hypoxia stress through ERF73/HRE1 (Hess et al., 2011).

Group VII ET-response factors (ERF-VIIs) play an important role in ET signal transduction and plant responses to waterlogging (Gasch et al., 2016; Giuntoli and Perata, 2018). 


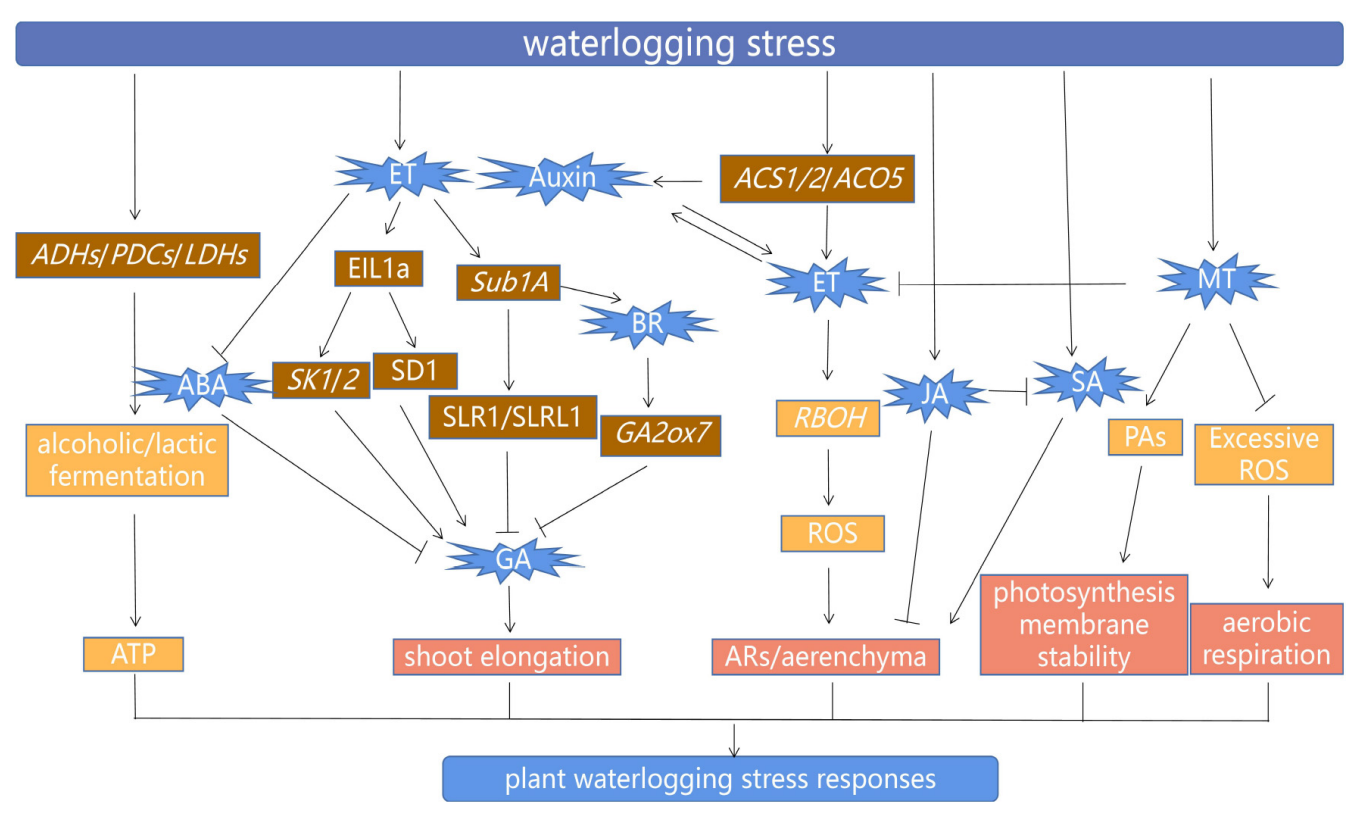

FIGURE 2 | Model of waterlogging response mechanism in plants. Arrows indicate positive stimuli; lines with blocked ends denote inhibitory effects. Waterlogging-tolerant plants can improve the rate of ethanol and lactic fermentation by enhancing the expression of $A D H s, P D C s$, and $L D H s$, whose gene products temporarily provide ATP for the growth of plants under waterlogging. OsEIL1a (an ethylene-responsive transcription factor) promotes SK1/2 transcription and also directly binds the promoter of GA biosynthesis gene SD1, thereby increasing the synthesis of GA, which stimulates shoot elongation. Increased ethylene levels (ET) inhibit ABA biosynthesis, which leads to increased GA content and induces shoot elongation in deepwater rice cultivars. However, in non-deepwater cultivars, Sub1A negatively regulates the GA response by limiting the degradation of the GA signal inhibitor protein SLR1/SLRL1, which inhibits shoot elongation. An increased BR level in Sub1A rice genotype induces the expression of GA catabolism gene GA2ox7, which represses GA signaling, so then shoot elongation is inhibited. In addition, the expression of $A C S$ and $A C O 5$ is induced in rice root aerenchyma under waterlogging, thereby promoting ethylene synthesis. Ethylene accumulation enhances auxin biosynthesis and transport, and vice versa. Ethylene enhances the expression of RBOH (NADPH oxidase, respiratory burst oxidase homolog) and induces ROS signals, which finally lead to the formation of ARs and aerenchyma. Furthermore, SA triggers a programmed cell death response, which leads to the development of aerenchyma cells. At the same time, the accumulation of SA stimulates the formation of AR primordia. JA inhibits AR growth and inhibits the action of SA under waterlogging. The application of MT enhanced tolerance to waterlogging stress by triggering the generation of PA biosynthesis, suppression of excessive ROS, and then improved photosynthetic machinery and aerobic respiration. Interestingly, the MT-treated plants under waterlogging stress exhibited decrease expression pattern of ethylene biosynthesis and signaling gene.

The gene ZmEREB180, a member of the ERF-VII family in maize, positively regulates the growth and development of ARs and the level of ROS: overexpression of ZmEREB180 in maize also improves the survival rate after long-term waterlogging stress (Yu et al., 2019). The PhERF2 protein binds directly with the promoter of ADH-related gene ADH1-2. PhERF2-RNAi lines had a mortality rate of $96 \%$ after flooding. Almost all PhERF2-overexpressing lines survived and showed faster and stronger recovery than WT plants (Yin et al., 2019).

The rice Sub1A (Submergence1A) gene is another member of the ET-response factor ERF-VII family. Overexpression of Sub1A enhanced the transcription of $A D H 1$ in transgenic rice and at the same time led to the enhanced ability to withstand waterlogging stress. Therefore, Sub1A gene could be the main determinant of submergence tolerance (Xu et al., 2006). Interestingly, the other two ERF-VII gene family members in rice, SK1/2 (SNORKEL1/2), can also regulate the waterlogging tolerance of rice. Overexpression of $S K 1 / 2$ led to internode elongation and significantly improved the waterlogging tolerance of deepwater rice cultivars (Hattori et al., 2009).

However, Sub1A and SK1/2 have opposite functions in regulating rice growth in response to waterlogging. Sub1A negatively regulates the GA response by limiting the degradation of the DELLA family protein SLR1 (Slender Rice-1), which are GA signal inhibitors, and thereby inhibits the elongation of rice (Fukao and Bailey-Serres, 2008; Hattori et al., 2009). Plants temporarily inhibit energy metabolism until water recedes, an effective long-term submergence strategy that occurs in rice mainly in non-deepwater cultivars (Xu et al., 2006; BaileySerres and Voesenek, 2008). In contrast, SK1/2 stimulates GA synthesis, which promotes rapid growth of rice stems and internode petioles, a structural change that allows rice leaves to respire normally once they have extended away from the water. The reason was found to be that submersion induced ET accumulation in rice and positively regulated the stability of OsEIL1a, an ET-responsive transcription factor (Kuroha et al., 2018). OsEIL1a protein promotes SK1/2 transcription by directly binding to the SK $1 / 2$ promoter, and then SK1/2 mediates the expression of downstream genes to initiate shoot elongation (Kuroha et al., 2018). OsEIL1a also directly binds and transcribes the promoter of GA biosynthesis gene SEMIDWARF1 (SD1), and SD1 protein promotes the synthesis of GA, mainly $\mathrm{GA}_{4}$, thus promoting shoot elongation (Kuroha et al., 2018). This evidence indicates that the 
OsEIL1a-SD1-SK1/2 cascade is closely related to waterlogging tolerance in deepwater rice cultivars.

\section{Abscisic Acid}

Abscisic acid (ABA) has a main role in regulating stomata by adjusting the size of guard cells, thereby regulating the water potential in plants. Because of this, ABA is considered to be a key hormone in water stress responses (Zhu, 2016; He et al., 2018).

Abscisic acid is involved in the development of root aerenchyma under waterlogging. The ABA concentration in soybean hypocotyls decreased rapidly under waterlogging, falling by $50 \%$ within $24 \mathrm{~h}$ compared with plants without waterlogging. In addition, secondary aeration tissues appeared after $72 \mathrm{~h}$. Exogenous $1 \mu \mathrm{M}$ ABA treatment inhibited the cell development of aerenchyma, suggesting that the formation of secondary aerenchyma required a reduction in the concentration of the negative regulatory factor ABA (Shimamura et al., 2014).

During waterlogging stress of Solanum dulcamara, following the rapid down-regulation of $\mathrm{ABA}$ biosynthesis and upregulation of $\mathrm{ABA}$ decomposition, the $\mathrm{ABA}$ concentration in the stem and AR primordia decreased sharply (Dawood et al., 2016). Waterlogging resulted in ET accumulation in the lower stem and subsequently reduced ABA concentrations in the stem and $A R$ primordia. $1 \mathrm{mM} \mathrm{ABA}$ treatment significantly inhibited the formation of ARs induced by waterlogging, whereas $100 \mu \mathrm{M}$ ABA inhibitor (Fluridone) induced AR production (Dawood et al., 2016). These results showed that ABA, in contrast to ET, negatively regulated the formation of ARs under waterlogging. Kim et al. (2015) determined the plant hormone content in soybeans after waterlogging for 5 and 10 days and found that the ABA content significantly decreased. The ABA content in waterlogging-resistant lines was significantly lower than that in sensitive lines, indicating that ABA might be negatively correlated with waterlogging tolerance. Waterlogging increased shoot elongation in deepwater rice cultivars partly by reducing the endogenous ABA content and thereby increasing the GA concentration (Yang and Choi, 2006). Similarly, ET and its precursor ACC rapidly induced the expression of OsABA8ox1. In addition, ET receptor inhibitor 1-MCP pretreatment partially inhibited the expression of OsABA8ox1. These results indicated that the rapid decline of $A B A$ in deepwater rice cultivars under waterlogging was partly controlled by ET-induced OsABA8ox1 expression (Saika et al., 2007).

The relative expression of the kiwifruit (Actinidia deliciosa) gene $A d P D C 1$ encoding pyruvate decarboxylase was significantly up-regulated under waterlogging, suggesting that the gene played an important role in the waterlogging response. ABA down-regulated the expression of $A d P D C 1$ under waterlogging, whereas the overexpression of AdPDC1 in Arabidopsis inhibited seed germination and root elongation under ABA treatment, indicating that $\mathrm{ABA}$ might negatively regulate $A d P D C 1$ under waterlogging (Zhang J.Y. et al., 2016).

However, other studies have shown that accumulation of $\mathrm{ABA}$ accelerated in the above-ground parts of the plant under waterlogging. ABA increased the accumulation of $\mathrm{H}_{2} \mathrm{O}_{2}$ and promoted stomatal closure, thus reducing the water loss from transpiration and improving the resistance of plants to waterlogging and related adverse environmental conditions. Overexpression of AP2/ERF family gene RAP2.6L in Arabidopsis promoted the expression of ABA biosynthesis genes, thus increasing ABA concentration. The increased ABA in RAP2.6Loverexpressing plants led to initiation of the antioxidant defense system and stomatal closure and finally resulted in reduced oxidative damage, delayed senescence, and significantly improved waterlogging tolerance (Liu et al., 2012). A significant increase in ABA content induced by waterlogging has been reported in cotton (Zhang Y. et al., 2016), wheat (Nan et al., 2002), and other crops. Komatsu et al. (2013) found that addition of 5, 10 , and $50 \mu \mathrm{M}$ ABA during waterlogging significantly improved soybean survival compared with waterlogging treatment alone. Similarly, pretreatment with $10 \mu \mathrm{M}$ ABA had recorded affirmative responses in rice net assimilation rate, relative growth rate, and chlorophyll content under submergence (Saha et al., 2021).

\section{Auxin}

Auxin (IAA) plays an important role in plant growth and development (Kazan and Manners, 2009; Lv et al., 2019). ET production, as an early response to waterlogging, can promote the transport of auxin, and conversely, the accumulation of auxin can prompt ET biosynthesis, further stimulating auxin transport to flooded parts of the plant, where the accumulation of auxin can induce ARs by initiating cell division. Exogenous application of the auxin transport inhibitor 1-naphthylphthalamic acid (NPA) to tomato (Vidoz et al., 2010), cucumber (Qi et al., 2019), and tobacco (McDonald and Visser, 2003) led to inhibition of AR growth after flooding.

The dynamic transport of auxin in plants is mediated by the auxin polar transport carrier protein PIN (PIN-FORMED), and treatment of rice with the transport inhibitor NPA decreased the expression of OsPIN2, suggesting that NPA might inhibit the production of ARs through an effect on PIN (Lin and Sauter, 2019). Similarly, when auxin polar transport was blocked in PIN expression-deficient mutants of $S$. dulcamara, the formation of ARs was inhibited, which further confirmed that AR production required auxin transport (Dawood et al., 2016).

However, some studies found that waterlogging reduced the content of IAA in soybean plants. Shimamura et al. (2016) found that the hypocotyl could form ARs and aerenchyma after $72 \mathrm{~h}$ of waterlogging, but physiological tests showed no significant difference within $72 \mathrm{~h}$ in the endogenous IAA concentration in the hypocotyl between the waterlogged and the control groups. This result showed that the accumulation of IAA was not a necessary condition for the formation of secondary aerenchyma in soybean hypocotyls under waterlogging.

Waterlogging can cause a large amount of carbohydrate consumption in plants, leading to energy shortage. Qi et al. (2020) first proposed a model for the interaction of sugars with auxininduced AR initiation and elongation in waterlogged cucumber. Under waterlogging stress and in light conditions, photosynthesis supported the biosynthesis of sugars, whose accumulation induced auxin transport and subsequent signal transduction, and finally induced the formation of ARs in the hypocotyl. 


\section{Gibberellin}

GAs are one of the essential plant hormones regulating growth and development. GAs regulate multiple processes in plant growth and development, mainly by controlling the size and number of cells (Nelissen et al., 2012).

Studies on different genotypes of soybean found that GA content in waterlogging-tolerant lines significantly increased under waterlogging, and GA content in waterlogging-resistant lines was significantly higher than that in waterlogging-sensitive lines (Kim et al., 2015). Huang et al. (2018) determined physiological indexes of peanuts (Arachis hypogaea) under waterlogging and found that spraying GA on the leaf surface could promote the growth of upper and underground parts of peanut plants and significantly increase the yield. Wang et al. (2016) showed that exogenous GA could effectively reduce the MDA content in the leaves and roots of rape under waterlogged conditions, thus improving the tolerance of plants to waterlogging.

Treatment with inhibitors of GA biosynthesis significantly reduced internode elongation in rice under waterlogging (Hattori et al., 2009; Ayano et al., 2014). Mutations in GA biosynthesis (Os1, OsCPS2, OsKS2, OsKS5, OsKO2, OsKAO, Os13ox, OsGA20ox1, OsGA20ox2, OsGA20ox3, OsGA3ox1, OsGA3ox2) and signal transduction genes (OsGID1, OsGID2, OsSPY, OsSEC, $O s G A M Y B$ ) also inhibited internode elongation (Ayano et al., 2014). Waterlogged rice plants treated with exogenous GA were able to restore internode elongation, enabling the leaves to respire normally once away from the flood water. GA has been shown to be a key hormone in improving rice tolerance under waterlogged conditions. Under waterlogging, GA participates in the $S K 1 / 2$ gene-mediated response pathway, and the GA content is up-regulated, leading to internode elongation. This structural change causes rice to extend above the water surface and reestablish gas exchange between plant tissue and the air (Hattori et al., 2009; Ayano et al., 2014). GA biosynthesis gene SD1 was shown to be the cause of internode elongation under waterlogging. When submerged, the SD1 gene was activated by OsEIL1a, an ET-responsive transcription factor, and SD1 protein promoted the synthesis of GA, mainly $\mathrm{GA}_{4}$, which promoted the rapid growth of leaf stalk internodes in rice (Kuroha et al., 2018). The results indicated that GA is centrally involved in promoting internode elongation in rice under waterlogged conditions.

\section{Salicylic Acid}

Salicylic acid (SA) is a common phenolic compound in plants, which regulates the antioxidant mechanism of cells by inducing the expression of stress-related genes, thus enhancing the adaptability of plants to adverse conditions (Zhou et al., 2009; Hayat et al., 2010; Arif et al., 2020).

Salicylic acid, as a signal substance, can induce changes in physiological characteristics of waterlogged plants. Peach trees (Prunus persica L.) were subjected to waterlogging stress. Spraying exogenous SA on day 1 of waterlogging can significantly increase the activities of ethanol dehydrogenase, protective enzymes such as POD and CAT, and the content of proline in leaves and roots, thereby protecting leaves and root membranes from damage and stabilizing photosynthetic capacity of leaves as well as root activity. Together, these protective effects are conducive to the alleviation of waterlogging-induced stress (Wang et al., 2015).

An increase of SA content might be an important factor in tolerance of waterlogging stress. Studies have shown that SA regulates two different physiological responses. First, an increase in intracellular SA triggers a programmed cell death response, leading to an increase in lipid peroxidation in the root cell walls, which in turn leads to the development of aerenchyma cells within the root. Aerenchyma cells can increase oxygen transfer into the root tissues and alleviate waterlogging stress. Second, the accumulation of SA stimulates the formation of AR primordia and further enhances waterlogging tolerance by inducing the development of a large number of ARs (Kim et al., 2015).

Kim et al. (2015) measured SA content in soybean after 5 and 10 days of waterlogging and found that the content of SA in waterlogging-tolerant soybean PI408105A was significantly higher than that in the unstressed control, whereas the content of SA in waterlogging-sensitive soybean S99-2281 was not significantly different from that in the control. Elevated SA would stimulate the formation of ARs, promote gas exchange, and ultimately enhance waterlogging tolerance. Bai et al. (2009) found that spraying exogenous SA alleviated oxidative stress damage caused by hypoxia stress on plants, and enhanced the hypoxia tolerance of Begonia occidentalis. The above results indicate that appropriate SA level can promote the formation of ARs and aerenchyma, which is positively correlated with the waterlogging tolerance of plants.

\section{Jasmonic Acid}

Jasmonic acid (JA) is a basic plant growth regulator that is known to be involved in the defense response produced by abiotic stress, but there are few studies on the relationship between JA and waterlogging tolerance (Per et al., 2018; Farhangi-Abriz and Ghassemi-Golezani, 2019; Raza et al., 2020; Wang J. et al., 2020).

$\mathrm{Xu}$ et al. (2016) found that the JA content in hypocotyl of Pepino, a waterlogging-sensitive cucumber line, was about twice that of the unstressed control after 2 days of waterlogging. However, JA content in the hypocotyl of the waterlogging-resistant line Zaoer-N decreased significantly during waterlogging to only 0.33 that of the control. The result suggested that JA is negatively correlated with the waterlogging tolerance of plants. However, other research showed that JA treatment inhibited root growth and the action of SA under waterlogging. Compared with the control, 649 different proteins were found in waterlogged soybeans treated with JA, which were mainly related to the stress response metabolite pathway, glycolysis, ethanol fermentation, and cell wall and cell tissue metabolism. The application of JA significantly reduced the damage to soybean plants under waterlogging and promoted plant growth by changing the proteomic profile (Kamal and Komatsu, 2016). There can be significant differences in JA content in different tissues of the same plant under waterlogging conditions. Under waterlogging stress, the JA content in citrus leaves increased significantly compared with the unstressed control, but the JA concentration in the root system 
decreased sharply. This might be caused by inhibition of the key lipoxygenase of the JA synthesis pathway under hypoxic conditions (Arbona and Gómez-Cadenas, 2008).

The interaction between JA and ET plays an important role in the formation and development of the root system and aerenchyma under waterlogging stress. Spraying methyl jasmonate on the leaves increased the content of ET (Hudgins and Franceschi, 2004). Thus, exogenous JA can increase the content of ET, which is beneficial in relieving waterlogging stress.

\section{Brassinosteroid}

Brassinosteroid (BR) is a naturally occurring steroid in plants. $\mathrm{BR}$ can induce resistance to a variety of biological and abiotic stresses, thus promoting plant growth and development (Bajguz and Hayat, 2009; Huang et al., 2020; Nazir et al., 2021).

Exogenous 24-epi-brassinolide (EBR) promotes the transfer of carbohydrates from leaves to roots of cucumber seedlings under hypoxic stress, enhances the activity of glycolytic enzymes in the roots, and triggers the antioxidant enzymes activity and reduced ROS production, thus improving the resistance of the seedlings to hypoxic stress (Kang et al., 2009). EBR also improved enzyme activity related to cell wall degradation by promoting ET production in cucumber seedlings. It further promoted the expansion and loosening of cucumber hypocotyl and formation of ARs, thus improving the oxygen supply status of the plant and enhancing the tolerance of the plant to hypoxic stress (Ma and Guo, 2014).

The Sub1A gene, an ET-response factor ERF-VII family member, has different regulatory effects on brassinolide biosynthetic gene expression and rice shoot elongation under waterlogging, compared with exogenous BR. Exogenous $\mathrm{BR}$ pretreatment can activate the tolerance mechanism in waterlogging-tolerant rice genotypes and inhibit shoot elongation under waterlogging. Compared to the LOES, higher expression of BR biosynthesis genes was observed in the Sub1A rice genotype, which triggered the endogenous $\mathrm{BR}$ level. The enhanced BR level induced the transcription of GA catabolism gene GA2ox7 resulting in reduced GA contents. At the same time, GA-mediated responses can be negatively regulated under submerged conditions by a DELLA family member, the GA-signal inhibitory factor SLR1 protein, so that the elongation of rice plants is inhibited (Schmitz et al., 2013). Therefore, BR limited shoot elongation by inhibiting GA biosynthesis and decreasing the action of GA in the rice Sub1A genotype.

Some selected recent studies on Phytohormones and plant growth regulator mediated waterlogging tolerance in plants are presented in Table 1.

\section{Melatonin}

Melatonin (MT) is a phytohormone and an excellent antioxidant molecule that augments plant growth under adverse conditions (Sharif et al., 2018). The MT has been previously reported for its mitigatory role of numerous abiotic stresses (Sharif et al., 2018). Owing to that, research related to MT and its involvement in improving waterlogging stress tolerance is relatively less, and only few research articles are available (Moustafa-Farag et al., 2020).

The very first report over MT in response to waterlogging stress unraveled that it can mend plant tolerance by inducing the activity of antioxidant enzymes, suppression of harmful ROS, and maintained proper growth to ensure good yield (Chen et al., 2015). Following that, the young apple seedlings subjected to waterlogging stress were treated with MT (Zheng et al., 2017). The study showed that seedling treated with MT presented enhanced tolerance to waterlogging stress by triggering the generation of antioxidant enzymes activities, improved aerobic respiration, and photosynthetic machinery (Zheng et al., 2017). On the other hand, the application of MT significantly inhibited the deleterious effects of anaerobic respiration and MDA- and ROS-induced chlorosis (Zheng et al., 2017). The induced expression level of MT biosynthesis genes such as $M b T 5 H 1, M b A A N A T 3$, and MbASMT9 increased the production of endogenous MT in the seedlings treated with MT (Zheng et al., 2017). Therefore, it can be assumed that MT plays a key role in regulating the response of plants to waterlogging stress. The growth of the alfalfa plant has been hampered by the waterlogging stress by dysfunctioning the photosynthetic ability and boosted the generation of electrolyte leakage and MDA contents (Zhang Q. et al., 2019). The up-regulated expression level of PA biosynthesis genes also highlighted their involvement in regulating the alfalfa response to waterlogging stress (Zhang Q. et al., 2019). The application of MT at the rate of $100 \mu \mathrm{M}$ over 6-week-old alfalfa seedlings displayed tolerance to waterlogging stress (Zhang Q. et al., 2019). The enhanced tolerance postMT application was associated with the further induction in the expression of PAs biosynthesis genes (SPDS, SPMS, and $A D C)$. Also, the exogenous MT treatment not only increased the endogenous MT level but also stabilized the normal functioning of other biochemical and physiological parameters (Zhang Q. et al., 2019). Further, the MT-treated plants under waterlogging stress exhibited decreased expression pattern of ET biosynthesis and signaling genes (ACS, ACO, and ERF) (Zhang Q. et al., 2019). This means that MT and ET possess an antagonistic relationship under waterlogging stress. However, no report is available to confirm the antagonistic crosstalk between MT and ET. P. persica is considered one of the most hypoxia-intolerant stone fruits. However, waterlogging, which causes hypoxia, occurs frequently in southern China, where peaches are commercially important (Gu et al., 2020). The application of MT at the rate of $200 \mu \mathrm{M}$ substantially augmented the antioxidant activities, suppressed the lipid peroxidation, and $\mathrm{H}_{2} \mathrm{O}_{2}$, positively regulated the size of aerenchyma for better anaerobic respiration activities and induced mRNA level of $\mathrm{Ca}^{2+}$ signaling and hypoxia-related ERF VII transcription factor genes (Gu et al., 2020). Therefore, it can be suggested that the application of MT positively regulates the ET homeostasis, which is an important and crucial factor in inducing waterlogging stress tolerance.

\section{INDUCING WATERLOGGING TOLERANCE VIA GENETIC ENGINEERING}

The manipulation of targeted plant genes to increase the production capacity or tolerance against a certain stress is becoming the need of the day (Lemay and Moineau, 2020). As the climate threat looms over the safe production of agronomic 
and horticultural crops, genome editing techniques can play a significant role in decreasing the adverse environmental effects (Lemay and Moineau, 2020). Previous studies have shown that the deleterious effects of the waterlogging stress can be mimicked by utilizing the genome editing tools. For example, the overexpression of AtACO5 gene in Arabidopsis triggered the ET production, and cell expansion activities resulted in enhanced tolerance against waterlogging stress (Rauf et al., 2013). The overexpression of CsARN6.1 gene in cucumber facilitates the formation of ARs independent of hormonal generations. However, the increased number of ARs in the overexpressed CsARN6.1 lines was associated with the intense cellular activities and hydrolysis of the ATP energy packets (Xu et al., 2018). The ERF transcription factors are directly involved in the regulation of waterlogging stress. A member of ERF transcription factor family PhERF2 was characterized in petunia (Yin et al., 2019). Upregulation in the transcript abundance of PhERF2 was observed under waterlogging stress. To further highlight the role, the PhERF2 overexpressed lines were generated, which displayed enhanced tolerance to waterlogging stress. On the contrary, the
RNAi line of PhERF2 showed sensitivity to waterlogging (Yin et al., 2019). The genes influence the alcoholic fermentation process such as ADH1-1, ADH1-2, ADH1-3, PDC1, and PDC2 induced and suppressed in overexpressed and silenced plants, respectively (Yin et al., 2019). Similarly, the induced expression levels of NtPDC, NtADH, NtHB1, NtHB2, NtPCO1, and NtPCO2 genes in AdRAP2.3 overexpressed tobacco plants presented its association with the enhanced waterlogging stress tolerance (Pan et al., 2019). In wheat, waterlogging stress can significantly hinder the physiological activities particularly photosynthesis, which ultimately reduce the grain yield and affect overall yield. The constitutive expression of TaERFVII.1 gene in wheat alleviated the negative effects of waterlogging stress by boosting the immunity resulting in increased grain weight per plant, improved survival rate, and better chlorophyll content of leaves (Wei et al., 2019). On the other hand, the compromised expression of TaERFVII. 1 in silenced plants also decreased the transcript of several waterlogging-responsive genes (Wei et al., 2019). Interestingly, the constitutive expression of TaERFVII.1 did not negatively impact both plant development and grain yield under

TABLE 2 | Listed studies related to improved waterlogging tolerance via genetic engineering.

\begin{tabular}{|c|c|c|c|c|}
\hline Plant species & Gene & Ways & Functional response & References \\
\hline Arabidopsis & AtACO5 and AtACS & Overexpression & $\begin{array}{l}\text { Overexpression of ACO5 and ACS genes enhanced } \\
\text { the generation of ethylene under waterlogging }\end{array}$ & Rauf et al., 2013 \\
\hline Arabidopsis & AtLDH & Overexpression & $\begin{array}{l}\text { Overexpression of } L D H \text { significantly enhanced the } \\
\text { PDC activity and hypoxia resistance }\end{array}$ & Dolferus et al., 2008 \\
\hline Arabidopsis & AtRAP2.6L & Overexpression & $\begin{array}{l}\text { Overexpression of } R A P 2.6 \mathrm{~L} \text { promoted the } \\
\text { expression of ABA biosynthesis genes, antioxidant } \\
\text { defense system, and stomatal closure }\end{array}$ & Liu et al., 2012 \\
\hline Oryza sativa & $\mathrm{RBOHH}$ & Knockout by CRISPR/Cas9 & $\begin{array}{l}\text { Knockout of the } \mathrm{RBOHH} \text { gene in rice reduces both } \\
\text { ROS accumulation and aerenchyma formation }\end{array}$ & Yamauchi et al., 2017 \\
\hline O. sativa & OsSK1 and OsSK2 & Overexpression & $\begin{array}{l}\text { Overexpression of SK1/2 led to internode } \\
\text { elongation }\end{array}$ & Hattori et al., 2009 \\
\hline O. sativa & OsSub1A & Overexpression & $\begin{array}{l}\text { Overexpression of Sub1A enhanced the } \\
\text { transcription of } A D H 1 \text { in transgenic rice and led to } \\
\text { the enhanced ability to withstand waterlogging } \\
\text { stress }\end{array}$ & $\begin{array}{l}\text { Xu et al., 2006; Fukao and } \\
\text { Bailey-Serres, 2008; Hattori } \\
\text { et al., } 2009\end{array}$ \\
\hline Maize & ZmEREB180 & Overexpression & $\begin{array}{l}\text { Overexpression of } Z m E R E B 180 \text { in maize improves } \\
\text { the survival rate after long-term waterlogging stress } \\
\text { via induced AR formation }\end{array}$ & Yu et al., 2019 \\
\hline Petunia & PhERF2 & Overexpression and RNAi & $\begin{array}{l}\text { PhERF2-RNAi lines had a mortality rate of } 96 \% \\
\text { after flooding. PhERF2-overexpressing lines } \\
\text { survived and showed faster and stronger recovery } \\
\text { than WT plants. }\end{array}$ & Yin et al., 2019 \\
\hline Kiwi fruit & AdRAP2.3 & Overexpression & $\begin{array}{l}\text { Overexpression of AdRAP2.3 in tobacco improved } \\
\text { the PDC and ADH enzyme activities and improved } \\
\text { the expression levels of waterlogging mark genes in } \\
\text { roots }\end{array}$ & Pan et al., 2019 \\
\hline Wheat & TaERFVII. 1 & Overexpression and VIGS & $\begin{array}{l}\text { The constitutive expression of TaERFVII. } 1 \text { gene in } \\
\text { wheat boosted the immunity and overall yield. The } \\
\text { silenced plants also decreased the transcript of } \\
\text { several waterlogging-responsive genes }\end{array}$ & Wei et al., 2019 \\
\hline Barley & HvERF2.11 & Overexpression & $\begin{array}{l}\text { HVERF2. } 11 \text { overexpression triggered the expression } \\
\text { level of antioxidant enzyme biosynthesis genes and } \\
\text { ethylene biosynthesis gene in Arabidopsis }\end{array}$ & Luan et al., 2020 \\
\hline Sunflower & HaHB11 & Overexpression & $\begin{array}{l}\text { Overexpressed in the Arabidopsis simultaneously } \\
\text { impacted tolerance and biomass in a positive } \\
\text { manner }\end{array}$ & Cabello et al., 2016 \\
\hline
\end{tabular}


standard conditions by suppressing the TaSAB18.1 gene (Wei et al., 2019). The barley HvERF2.11 when overexpressed in Arabidopsis triggered the expression level of antioxidant enzyme biosynthesis genes (AtSOD1, AtPOD1) and ET biosynthesis gene (AtACO1), conferring resistance to waterlogging stress (Luan et al., 2020). The HD-ZIP I subfamily gene HaHB11 was overexpressed in the Arabidopsis and exposed to waterlogging stress (Cabello et al., 2016). The transgenic Arabidopsis plants carrying gain-of-function $\mathrm{HaHB11}$ gene not only induced the tolerance to waterlogging stress but also increased the biomass and yielded more seeds than control by inducing the glucose and sucrose level (Cabello et al., 2016). In addition, the HaHB11 were notably involved in the increment of expression of genes involved in the alcohol fermentation (Cabello et al., 2016). Multiple studies highlighting the importance of genetic engineering in augmenting the immunity of plants to waterlogging stress are presented in Table 2.

\section{CONCLUSION AND OUTLOOK}

The regulation of plant growth and development processes under waterlogging stress is very complex, with different crops, different varieties of the same crop, and different growth periods of the same crop often showing great differences, while different plant species evolved different adaptation strategies. At present, research on crop waterlogging tolerance is mainly carried out from the perspective of morphological, structural, physiological, biochemical, and metabolic gene signal regulation. The most effective ways to enhance plant waterlogging tolerance will be (1) improving cultivation management to reduce the direct damage to crops caused by waterlogging and (2) using modern molecular biology technology to discover the key genes regulating waterlogging tolerance and verify their functions.

Building on existing research results and aiming to address identified problems, the following aspects should receive increased attention in future research on plant waterlogging tolerance:

(1) Current studies focus mainly on the vegetative growth stage of plants under waterlogging stress. However, the molecular responses during seed germination, early seedling morphogenesis, and late reproductive growth under waterlogging stress are neglected topics that warrant further study.

(2) Although a large number of related genes regulating plant waterlogging tolerance have been obtained by transcriptomics, proteomics, and other methods. However,

\section{REFERENCES}

Abiko, T., and Miyasaka, S. C. (2020). Aerenchyma and barrier to radial oxygen loss are formed in roots of Taro (Colocasia esculenta) propagules under flooded conditions. J. Plant Res. 133, 49-56. doi: 10.1007/s10265-019-01150-6

Alpuerto, J. B., Hussain, R. M. F., and Fukao, T. (2016). The key regulator of submergence tolerance, SUB1A, promotes photosynthetic and metabolic recovery from submergence damage in rice leaves. Plant Cell Environ. 39, 672-684. doi: $10.1111 /$ pce. 12661 most of them are preliminary study and required functional characterization.

(3) There is a need to exploit additional genetic resources for waterlogging tolerance, using both isolated populations and natural populations to identify waterlogging tolerance-related genes.

(4) The hormonal-induced waterlogging resistance has been studied extensively. Majority of the available studies mainly reported the effects of growth hormones on vegetative stages under waterlogging stress. Although studies are missing to investigate the role of these phytohormones when waterlogging stress happens at reproductive stages of the plant. Hormonal crosstalk under waterlogging stress in the early developmental stages of plant has been investigated and is presented in Figure 2. However, it could be interesting to examine the complex hormonal crosstalk under waterlogging stress during reproductive stages, such as how these hormones ensure plant productivity under prolonged waterlogging stress. Additionally, is there an unknown genetic factor(s) controlling phytohormone-mediated cascades under waterlogging condition? Therefore, it is of great importance to elucidate these mechanisms to develop waterlogging resilience plants to increase crop productivity particularly in the areas that have poor soil drainage properties, those affected by frequent heavy rainfall, and areas with duplex soil.

\section{AUTHOR CONTRIBUTIONS}

JP wrote the manuscript. RS, XX, and XC revised and finally approved the manuscript for publication. All the authors contributed to the article and approved the submitted version.

\section{FUNDING}

This research was supported by the National Natural Science Foundation of China (grant nos. 32030093 and 31801883) and Natural Science Foundation of Jiangsu Province (BK20180913).

\section{ACKNOWLEDGMENTS}

We thank Dr. Qi Xioahua (College of Horticulture and Plant Protection, Yangzhou University) for critically revising the manuscript. 0147202

Andrade, C. A., de Souza, K. R. D., de Oliveira Santos, M., da Silva, D. M., and Alves, J. D. (2018). Hydrogen peroxide promotes the tolerance of soybeans to waterlogging. Sci. Horticult. 232, 40-45. doi: 10.1016/j.scienta.2017.12.048

Anee, T. I., Nahar, K., Rahman, A., Mahmud, J. A., Bhuiyan, T. F., Alam, M. U., et al. (2019). Oxidative damage and antioxidant defense in Sesamum indicum after different waterlogging durations. Plants 8:196. doi: 10.3390/plants8070196 
Arbona, V., and Gómez-Cadenas, A. (2008). Hormonal modulation of citrus responses to flooding. J. Plant Growth Regulat. 27:241. doi: 10.1007/s00344008-9051-X

Arif, Y., Sami, F., Siddiqui, H., Bajguz, A., and Hayat, S. (2020). Salicylic acid in relation to other phytohormones in plant: a study towards physiology and signal transduction under challenging environment. Environ. Exp. Bot. 175:104040. doi: 10.1016/j.envexpbot.2020.104040

Ayano, M., Kani, T., Kojima, M., Sakakibara, H., Kitaoka, T., Kuroha, T., et al. (2014). Gibberellin biosynthesis and signal transduction is essential for internode elongation in deepwater rice. Plant Cell Environ. 37, 2313-2324. doi: $10.1111 /$ pce. 12377

Bai, T., Li, C., Ma, F., Shu, H., and Han, M. (2009). Exogenous salicylic acid alleviates growth inhibition and oxidative stress induced by hypoxia stress in Malus robusta Rehd. J. Plant Growth Regulat. 28, 358-366. doi: 10.1007/s00344009-9104-9

Bailey-Serres, J., and Chang, R. (2005). Sensing and signalling in response to oxygen deprivation in plants and other organisms. Ann. Bot. 96, 507-518. doi: $10.1093 / \mathrm{aob} / \mathrm{mci} 206$

Bailey-Serres, J., and Voesenek, L. (2008). Flooding stress: acclimations and genetic diversity. Annu. Rev. Plant Biol. 59, 313-339. doi: 10.1146/annurev.arplant.59. 032607.092752

Bailey-Serres, J., Fukao, T., Gibbs, D. J., Holdsworth, M. J., Lee, S. C., Licausi, F., et al. (2012). Making sense of low oxygen sensing. Trends Plant Sci. 17, 129-138.

Bajguz, A., and Hayat, S. (2009). Effects of brassinosteroids on the plant responses to environmental stresses. Plant Physiol. Biochem. 47, 1-8. doi: 10.1016/j. plaphy.2008.10.002

Bansal, R., and Srivastava, J. P. (2012). Antioxidative defense system in pigeonpea roots under waterlogging stress. Acta Physiol. Plant. 34, 515-522. doi: 10.1007/ s11738-011-0848-z

Bartoli, C. G., Casalongué, C. A., Simontacchi, M., Marquez-Garcia, B., and Foyer, C. H. (2013). Interactions between hormone and redox signalling pathways in the control of growth and cross tolerance to stress. Environ. Exp. Bot. 94, 73-88. doi: 10.1016/j.envexpbot.2012.05.003

Baxter, A., Mittler, R., and Suzuki, N. (2014). ROS as key players in plant stress signalling. J. Exp. Bot. 65, 1229-1240. doi: 10.1093/jxb/ert375

Baxter-Burrell, A., Yang, Z., Springer, P. S., and Bailey-Serres, J. (2002). RopGAP4dependent Rop GTPase rheostat control of Arabidopsis oxygen deprivation tolerance. Science 296, 2026-2028. doi: 10.1126/science.1071505

Benschop, J. J., Bou, J., Peeters, A. J., Wagemaker, N., Gühl, K., Ward, D., et al. (2006). Long-term submergence-induced elongation in Rumex palustris requires abscisic acid-dependent biosynthesis of gibberellin1. Plant Physiol. 141, 1644-1652. doi: 10.1104/pp.106.082636

Bin, T., Xu, S.-Z., Zou, X.-L., Zheng, Y.-L., and Qiu, F.-Z. (2010). Changes of antioxidative enzymes and lipid peroxidation in leaves and roots of waterlogging-tolerant and waterlogging-sensitive maize genotypes at seedling stage. Agricult. Sci. China 9, 651-661. doi: 10.1016/s1671-2927(09)60140-1

Borella, J., Becker, R., Lima, M. C., Oliveira, D. D. S. C. D., Braga, E. J. B., Oliveira, A. C. B. D., et al. (2019). Nitrogen source influences the antioxidative system of soybean plants under hypoxia and re-oxygenation. Sci. Agricol. 76, 51-62. doi: 10.1590/1678-992x-2017-0195

Cabello, J. V., Giacomelli, J. I., Piattoni, C. V., Iglesias, A. A., and Chan, R. L. (2016). The sunflower transcription factor HaHB11 improves yield, biomass and tolerance to flooding in transgenic Arabidopsis plants. J. Biotechnol. 222, 73-83. doi: 10.1016/j.jbiotec.2016.02.015

Caruso, P., Baldoni, E., Mattana, M., Paolo, D. P., Genga, A., Coraggio, I., et al. (2012). Ectopic expression of a rice transcription factor, Mybleu, enhances tolerance of transgenic plants of Carrizo citrange to low oxygen stress. Plant Cell Tissue Organ Cult. (PCTOC) 109, 327-339. doi: 10.1007/s11240-011-0098-1

Chen, H., Feng, C., Kong, J., Wang, L., Wang, N., Zheng, X., et al. (2015). Use of product containing melatonin as effective component for improving waterlogging stress resistance in plants. Google Patent No. A01N-043/38 201612.

Colmer, T. (2002). Aerenchyma and an inducible barrier to radial oxygen loss facilitate root aeration in upland, paddy and deep-water rice (Oryza sativa L.). Ann. Bot. 91, 301-309. doi: 10.1093/aob/mcf114

Dawood, T., Yang, X., Visser, E. J., Te Beek, T. A., Kensche, P. R., Cristescu, S. M., et al. (2016). A co-opted hormonal cascade activates dormant adventitious root primordia upon flooding in Solanum dulcamara. Plant Physiol. 170, 2351-2364. doi: 10.1104/pp.15.00773
Ding, J., Liang, P., Wu, P., Zhu, M., Li, C., Zhu, X., et al. (2020). Effects of waterlogging on grain yield and associated traits of historic wheat cultivars in the middle and lower reaches of the Yangtze River, China. Field Crops Res. 246:107695. doi: 10.1016/j.fcr.2019.107695

Dolferus, R., Wolansky, M., Carroll, R., Miyashita, Y., Ismond, K., and Good, A. (2008). Functional analysis of lactate dehydrogenase during hypoxic stress in Arabidopsis. Funct. Plant Biol. 35, 131-140. doi: 10.1071/fp07228

Doupis, G., Kavroulakis, N., Psarras, G., and Papadakis, I. (2017). Growth, photosynthetic performance and antioxidative response of 'Hass' and 'Fuerte'avocado (Persea americana Mill.) plants grown under high soil moisture. Photosynthetica 55, 655-663. doi: 10.1007/s11099-016-0679-7

Drew, M. C., He, C.-J., and Morgan, P. W. (2000). Programmed cell death and aerenchyma formation in roots. Trends Plant Sci. 5, 123-127. doi: 10.1016/ s1360-1385(00)01570-3

Evans, D. E. (2004). Aerenchyma formation. New Phytol. 161, 35-49. doi: 10.1046/ j.1469-8137.2003.00907.x

Eysholdt-Derzsó, E., and Sauter, M. (2019). Hypoxia and the group VII ethylene response transcription factor HRE2 promote adventitious root elongation in Arabidopsis. Plant Biol. 21, 103-108. doi: 10.1111/plb.12873

Farhangi-Abriz, S., and Ghassemi-Golezani, K. (2019). Jasmonates: mechanisms and functions in abiotic stress tolerance of plants. Biocatalys. Agricult. Biotechnol. 20:101210. doi: 10.1016/j.bcab.2019.101210

Fukao, T., and Bailey-Serres, J. (2008). Submergence tolerance conferred by Sub1A is mediated by SLR1 and SLRL1 restriction of gibberellin responses in rice. Proc. Natl. Acad. Sci. U.S.A. 105, 16814-16819. doi: 10.1073/pnas.080782 1105

Fukao, T., Barrera-Figueroa, B. E., Juntawong, P., and Peña-Castro, J. M. (2019). Submergence and waterlogging stress in plants: a review highlighting research opportunities and understudied aspects. Front. Plant Sci. 10:340. doi: 10.3389/ fpls.2019.00340

Fukao, T., Xu, K., Ronald, P. C., and Bailey-Serres, J. (2006). A variable cluster of ethylene response factor-like genes regulates metabolic and developmental acclimation responses to submergence in rice. Plant Cell 18, 2021-2034. doi: 10.1105/tpc. 106.043000

Gasch, P., Fundinger, M., Müller, J. T., Lee, T., Bailey-Serres, J., and Mustroph, A. (2016). Redundant ERF-VII transcription factors bind to an evolutionarily conserved cis-motif to regulate hypoxia-responsive gene expression in Arabidopsis. Plant Cell 28, 160-180. doi: 10.1105/tpc.15.00866

Giuntoli, B., and Perata, P. (2018). Group VII ethylene response factors in Arabidopsis: regulation and physiological roles. Plant Physiol. 176, 1143-1155. doi: $10.1104 /$ pp.17.01225

Gu, X., Xue, L., Lu, L., Xiao, J., Song, G., Xie, M., et al. (2020). Melatonin Enhances the waterlogging tolerance of prunus persica by modulating antioxidant metabolism and anaerobic respiration. J. Plant Growth Regulat. 1-13. doi: 10.9734/ijbcrr/2016/32087

Hartman, S., Liu, Z., Van Veen, H., Vicente, J., Reinen, E., Martopawiro, S., et al. (2019a). Ethylene-mediated nitric oxide depletion pre-adapts plants to hypoxia stress. Nat. Commun. 10, 1-9.

Hartman, S., Sasidharan, R., and Voesenek, L. A. (2019b). The role of ethylene in metabolic acclimations to low oxygen. New Phytol. 229, 64-70. doi: 10.1111/ nph.16378

Hasanuzzaman, M., Bhuyan, M., Zulfiqar, F., Raza, A., Mohsin, S. M., Mahmud, J. A., et al. (2020). Reactive oxygen species and antioxidant defense in plants under abiotic stress: revisiting the crucial role of a universal defense regulator. Antioxidants 9:681. doi: 10.3390/antiox9080681

Hattori, Y., Nagai, K., Furukawa, S., Song, X.-J., Kawano, R., Sakakibara, H., et al. (2009). The ethylene response factors SNORKEL1 and SNORKEL2 allow rice to adapt to deep water. Nature 460, 1026-1030. doi: 10.1038/nature08258

Hayat, Q., Hayat, S., Irfan, M., and Ahmad, A. (2010). Effect of exogenous salicylic acid under changing environment: a review. Environ. Exp. Bot. 68, 14-25. doi: 10.1016/j.envexpbot.2009.08.005

He, F., Wang, H.-L., Li, H.-G., Su, Y., Li, S., Yang, Y., et al. (2018). PeCHYR 1, a ubiquitin E3 ligase from Populus euphratica, enhances drought tolerance via $\mathrm{ABA}$-induced stomatal closure by ROS production in Populus. Plant Biotechnol. J. 16, 1514-1528. doi: 10.1111/pbi.12893

Herzog, M., Striker, G. G., Colmer, T. D., and Pedersen, O. (2016). Mechanisms of waterlogging tolerance in wheat-a review of root and shoot physiology. Plant Cell Environ. 39, 1068-1086. doi: 10.1111/pce. 12676 
Hess, N., Klode, M., Anders, M., and Sauter, M. (2011). The hypoxia responsive transcription factor genes ERF71/HRE2 and ERF73/HRE1 of Arabidopsis are differentially regulated by ethylene. Physiol. Plant. 143, 41-49. doi: 10.1111/j. 1399-3054.2011.01486.x

Hirabayashi, Y., Mahendran, R., Koirala, S., Konoshima, L., Yamazaki, D., Watanabe, S., et al. (2013). Global flood risk under climate change. Nat. Clim. Change 3, 816-821. doi: 10.1038/nclimate1911

Hossain, M. A., Bhattacharjee, S., Armin, S.-M., Qian, P., Xin, W., Li, H.-Y., et al. (2015). Hydrogen peroxide priming modulates abiotic oxidative stress tolerance: insights from ROS detoxification and scavenging. Front. Plant Sci. 6:420. doi: 10.3389/fpls.2015.00420

Huang, H., Liu, D., Li, L., Wu, J., Wang, S., and Li, X. (2018). Effects of spraying plant growth regulators on peanut growth and yield \& quality under waterlogging stress. J. Hum. Agric. Univ. 44, 129. (in Chinese),

Huang, L., Zhang, L., Zeng, R., Wang, X., Zhang, H., Wang, L., et al. (2020). Brassinosteroid priming improves peanut drought tolerance via eliminating inhibition on genes in photosynthesis and hormone signaling. Genes 11, 919. doi: 10.3390/genes11080919

Hudgins, J., and Franceschi, V. R. (2004). Methyl jasmonate-induced ethylene production is responsible for conifer phloem defense responses and reprogramming of stem cambial zone for traumatic resin duct formation. Plant Physiol. 135, 2134-2149. doi: 10.1104/pp.103.037929

Kamal, A. H. M., and Komatsu, S. (2016). Jasmonic acid induced protein response to biophoton emissions and flooding stress in soybean. J. Proteom. 133, 33-47. doi: 10.1016/j.jprot.2015.12.004

Kang, Y.-Y., Guo, S.-R., Li, J., and Duan, J.-J. (2009). Effect of root applied 24epibrassinolide on carbohydrate status and fermentative enzyme activities in cucumber (Cucumis sativus L.) seedlings under hypoxia. Plant Growth Regul. 57, 259-269. doi: 10.1007/s10725-008-9344-x

Kazan, K., and Manners, J. M. (2009). Linking development to defense: auxin in plant-pathogen interactions. Trends Plant Sci. 14, 373-382. doi: 10.1016/j. tplants.2009.04.005

Kim, Y., Seo, C.-W., Khan, A. L., Mun, B.-G., Shahzad, R., Ko, J.-W., et al. (2018). Exo-ethylene application mitigates waterlogging stress in soybean (Glycine max L.). BMC Plant Biol. 18:254. doi: 10.1186/s12870-018-1457-4

Kim, Y.-H., Hwang, S.-J., Waqas, M., Khan, A. L., Lee, J.-H., Lee, J.-D., et al. (2015). Comparative analysis of endogenous hormones level in two soybean (Glycine max L.) lines differing in waterlogging tolerance. Front. Plant Sci. 6:714. doi: 10.3389/fpls.2015.00714

Komatsu, S., Han, C., Nanjo, Y., Altaf-Un-Nahar, M., Wang, K., He, D., et al. (2013). Label-free quantitative proteomic analysis of abscisic acid effect in earlystage soybean under flooding. J. Proteome Res. 12, 4769-4784. doi: 10.1021/ pr4001898

Komatsu, S., Thibaut, D., Hiraga, S., Kato, M., Chiba, M., Hashiguchi, A., et al. (2011). Characterization of a novel flooding stress-responsive alcohol dehydrogenase expressed in soybean roots. Plant Mol. Biol. 77, 309-322. doi: 10.1007/s11103-011-9812-y

Kreuzwieser, J., and Rennenberg, H. (2014). Molecular and physiological responses of trees to waterlogging stress. Plant Cell Environ. 37, 22452259.

Kuai, J., Liu, Z., Wang, Y., Meng, Y., Chen, B., Zhao, W., et al. (2014). Waterlogging during flowering and boll forming stages affects sucrose metabolism in the leaves subtending the cotton boll and its relationship with boll weight. Plant Sci. 223, 79-98. doi: 10.1016/j.plantsci.2014.03.010

Kuroha, T., Nagai, K., Gamuyao, R., Wang, D. R., Furuta, T., Nakamori, M., et al. (2018). Ethylene-gibberellin signaling underlies adaptation of rice to periodic flooding. Science 361, 181-186. doi: 10.1126/science.aat1577

Kurokawa, Y., Nagai, K., Huan, P. D., Shimazaki, K., Qu, H., Mori, Y., et al. (2018). Rice leaf hydrophobicity and gas films are conferred by a wax synthesis gene (LGF 1) and contribute to flood tolerance. New Phytol. 218, 1558-1569. doi: $10.1111 /$ nph. 15070

Lee, Y.-H., Kim, K.-S., Jang, Y.-S., Hwang, J.-H., Lee, D.-H., and Choi, I.-H. (2014). Global gene expression responses to waterlogging in leaves of rape seedlings. Plant Cell Rep. 33, 289-299. doi: 10.1007/s00299-013-1529-8

Lemay, M.-L., and Moineau, S. (2020). "How are genes modified? Crossbreeding, mutagenesis, and CRISPR-Cas9," in Genetically Modified and Irradiated Food, ed. V. Andersen (Cambridge, MA: Academic Press), 39-54. doi: 10.1016/b9780-12-817240-7.00003-6
Li, C.-X., Wei, H., Geng, Y.-H., and Schneider, R. (2010). Effects of submergence on photosynthesis and growth of Pterocarya stenoptera (Chinese wingnut) seedlings in the recently-created Three Gorges Reservoir region of China. Wetl. Ecol. Manag. 18, 485-494. doi: 10.1007/s11273-010-9181-3

Li, T. (2007). Preliminary Studies of Waterlogging in Physiology of Cucumber at the Seedling Stage. Doctoral Dissertation, University of Yangzhou, China.

Li, W., Mo, W., Ashraf, U., Li, G., Wen, T., Abrar, M., et al. (2018). Evaluation of physiological indices of waterlogging tolerance of different maize varieties in South China. Appl. Ecol. Environ. Res. 16, 2059-2072. doi: 10.15666/aeer/1602_ 20592072

Limami, A. M., Diab, H., and Lothier, J. (2014). Nitrogen metabolism in plants under low oxygen stress. Planta 239, 531-541. doi: 10.1007/s00425-013-2015-9

Lin, C., and Sauter, M. (2019). Polar auxin transport determines adventitious root emergence and growth in rice. Front. Plant Sci. 10:444. doi: 10.3389/fpls.2019. 00444

Lin, K.-H. R., Weng, C.-C., Lo, H.-F., and Chen, J.-T. (2004). Study of the root antioxidative system of tomatoes and eggplants under waterlogged conditions. Plant Sci. 167, 355-365. doi: 10.1016/j.plantsci.2004.04.004

Liu, B., Sun, L., Ma, L., and Hao, F.-S. (2017). Both AtrbohD and AtrbohF are essential for mediating responses to oxygen deficiency in Arabidopsis. Plant Cell Rep. 36, 947-957. doi: 10.1007/s00299-017-2128-x

Liu, P., Sun, F., Gao, R., and Dong, H. (2012). RAP2. 6L overexpression delays waterlogging induced premature senescence by increasing stomatal closure more than antioxidant enzyme activity. Plant Mol. Biol. 79, 609-622. doi: 10.1007/s11103-012-9936-8

Loreti, E., van Veen, H., and Perata, P. (2016). Plant responses to flooding stress. Curr. Opin. Plant Biol. 33, 64-71. doi: 10.1016/j.pbi.2016.06.005

Luan, H., Guo, B., Shen, H., Pan, Y., Hong, Y., Lv, C., et al. (2020). Overexpression of Barley Transcription Factor HvERF2. 11 in Arabidopsis enhances plant waterlogging tolerance. Int. J. Mol. Sci. 21, 1982. doi: 10.3390/ijms21061982

Luan, H., Shen, H., Pan, Y., Guo, B., Lv, C., and Xu, R. (2018). Elucidating the hypoxic stress response in barley (Hordeum vulgare L.) during waterlogging: a proteomics approach. Sci. Rep. 8, 1-13.

Lv, B., Yan, Z., Tian, H., Zhang, X., and Ding, Z. (2019). Local auxin biosynthesis mediates plant growth and development. Trends Plant Sci. 24, 6-9. doi: 10. 1016/j.tplants.2018.10.014

Ma, Y., and Guo, S. (2014). 24-epibrassinolide improves cucumber photosynthesis under hypoxia by increasing $\mathrm{CO} 2$ assimilation and photosystem II efficiency. Photosynthetica 52, 96-104. doi: 10.1007/s11099-014-0010-4

McDonald, M., and Visser, E. (2003). A study of the interaction between auxin and ethylene in wild type and transgenic ethylene-insensitive tobacco during adventitious root formation induced by stagnant root zone conditions. Plant Biol. 5, 550-556. doi: 10.1055/s-2003-44790

Mignolli, F., Todaro, J. S., and Vidoz, M. L. (2020). Internal aeration and respiration of submerged tomato hypocotyls are enhanced by ethylenemediated aerenchyma formation and hypertrophy. Physiol. Plant. 169, 49-63. doi: $10.1111 /$ ppl.13044

Miransari, M., and Smith, D. (2014). Plant hormones and seed germination. Environ. Exp. Bot. 99, 110-121. doi: 10.1016/j.envexpbot.2013.11.005

Mondal, S., Khan, M. I. R., Dixit, S., Cruz, P. C. S., Septiningsih, E. M., and Ismail, A. M. (2020). Growth, productivity and grain quality of AG1 and AG2 QTLs introgression lines under flooding in direct-seeded rice system. Field Crops Res. 248, 107713. doi: 10.1016/j.fcr.2019.107713

Moustafa-Farag, M., Mahmoud, A., Arnao, M. B., Sheteiwy, M. S., Dafea, M., Soltan, M., et al. (2020). Melatonin-induced water stress tolerance in plants: recent advances. Antioxidants 9, 809. doi: 10.3390/antiox9090809

Nan, R., Carman, J. G., and Salisbury, F. B. (2002). Water stress, CO2 and photoperiod influence hormone levels in wheat. J. Plant Physiol. 159, 307-312. doi: 10.1078/0176-1617-00703

Nazir, F., Fariduddin, Q., Hussain, A., and Khan, T. A. (2021). Brassinosteroid and hydrogen peroxide improve photosynthetic machinery, stomatal movement, root morphology and cell viability and reduce $\mathrm{Cu}$-triggered oxidative burst in tomato. Ecotoxicol. Environ. Saf. 207, 111081. doi: 10.1016/j.ecoenv.2020. 111081

Nelissen, H., Rymen, B., Jikumaru, Y., Demuynck, K., Van Lijsebettens, M., Kamiya, Y., et al. (2012). A local maximum in gibberellin levels regulates maize leaf growth by spatial control of cell division. Curr. Biol. 22, 1183-1187. doi: 10.1016/j.cub.2012.04.065 
Nishiuchi, S., Yamauchi, T., Takahashi, H., Kotula, L., and Nakazono, M. (2012). Mechanisms for coping with submergence and waterlogging in rice. Rice 5, 2. doi: 10.1186/1939-8433-5-2

Pan, D.-L., Wang, G., Wang, T., Jia, Z.-H., Guo, Z.-R., and Zhang, J.-Y. (2019). AdRAP2. 3, a novel ethylene response factor VII from Actinidia deliciosa, enhances waterlogging resistance in transgenic tobacco through improving expression levels of PDC and ADH Genes. Int. J. Mol. Sci. 20, 1189. doi: 10.3390/ijms20051189

Pedersen, O., Rich, S. M., and Colmer, T. D. (2009). Surviving floods: leaf gas films improve $\mathrm{O} 2$ and $\mathrm{CO} 2$ exchange, root aeration, and growth of completely submerged rice. Plant J. 58, 147-156. doi: 10.1111/j.1365-313x.2008.03769.x

Pedersen, O., Sauter, M., Colmer, T. D., and Nakazono, M. (2020). Regulation of root adaptive anatomical and morphological traits during low soil oxygen. New Phytol. 229, 42-49. doi: 10.1111/nph.16375

Per, T. S., Khan, M. I. R., Anjum, N. A., Masood, A., Hussain, S. J., and Khan, N. A. (2018). Jasmonates in plants under abiotic stresses: crosstalk with other phytohormones matters. Environ. Exp. Bot. 145, 104-120. doi: 10.1016/j. envexpbot.2017.11.004

Pucciariello, C., Parlanti, S., Banti, V., Novi, G., and Perata, P. (2012). Reactive oxygen species-driven transcription in Arabidopsis under oxygen deprivation. Plant Physiol. 159, 184-196. doi: 10.1104/pp.111.191122

Qi, X., Li, Q., Ma, X., Qian, C., Wang, H., Ren, N., et al. (2019). Waterlogginginduced adventitious root formation in cucumber is regulated by ethylene and auxin through reactive oxygen species signalling. Plant Cell Environ. 42, 1458-1470. doi: 10.1111/pce.13504

Qi, X., Li, Q., Shen, J., Qian, C., Xu, X., Xu, Q., et al. (2020). Sugar enhances waterlogging-induced adventitious root formation in cucumber by promoting auxin transport and signalling. Plant Cell Environ. 43, 1545-1557. doi: 10.1111/ pce. 13738

Rauf, M., Arif, M., Fisahn, J., Xue, G.-P., Balazadeh, S., and Mueller-Roeber, B. (2013). NAC transcription factor speedy hyponastic growth regulates floodinginduced leaf movement in Arabidopsis. Plant Cell 25, 4941-4955. doi: 10.1105/ tpc. 113.117861

Raza, A., Charagh, S., Zahid, Z., Mubarik, M. S., Javed, R., Siddiqui, M. H., et al. (2020). Jasmonic acid: a key frontier in conferring abiotic stress tolerance in plants. Plant Cell Rep.[Epub ahead of print].

Saha, I., Hasanuzzaman, M., Dolui, D., Sikdar, D., Debnath, S. C., and Adak, M. K. (2021). Silver-nanoparticle and abscisic acid modulate sub1A quantitative trait loci functioning towards submergence tolerance in rice (Oryza sativa L.). Environ. Exp. Bot. 181, 1042276.

Saika, H., Okamoto, M., Miyoshi, K., Kushiro, T., Shinoda, S., Jikumaru, Y., et al. (2007). Ethylene promotes submergence-induced expression of OsABA8ox1, a gene that encodes ABA 8'-hydroxylase in rice. Plant Cell Physiol. 48, 287-298. doi: $10.1093 / \mathrm{pcp} / \mathrm{pcm} 003$

Salah, A., Zhan, M., Cao, C., Han, Y., Ling, L., Liu, Z., et al. (2019). $\gamma$-Aminobutyric acid promotes chloroplast ultrastructure, antioxidant capacity, and growth of waterlogged maize seedlings. Sci. Rep. 9, 1-19.

Sasidharan, R., and Voesenek, L. A. (2015). Ethylene-mediated acclimations to flooding stress. Plant Physiol. 169, 3-12. doi: 10.1104/pp.15.00387

Schmitz, A. J., Folsom, J. J., Jikamaru, Y., Ronald, P., and Walia, H. (2013). SUB $1 \mathrm{~A}-$ mediated submergence tolerance response in rice involves differential regulation of the brassinosteroid pathway. New Phytol. 198, 1060-1070. doi: 10.1111/nph.12202

Sharif, R., Xie, C., Zhang, H., Arnao, M. B., Ali, M., Ali, Q., et al. (2018). Melatonin and its effects on plant systems. Molecules 23, 2352. doi: 10.3390/ molecules23092352

Sharma, P., Jha, A. B., Dubey, R. S., and Pessarakli, M. (2012). Reactive oxygen species, oxidative damage, and antioxidative defense mechanism in plants under stressful conditions. J. Bot. 2012, 217037.

Shimamura, S., Nishimura, T., Koshiba, T., Yamamoto, R., Hiraga, S., Nakamura, T., et al. (2016). Effects of anti-auxins on secondary aerenchyma formation in flooded soybean hypocotyls. Plant Prod. Sci. 19, 154-160. doi: 10.1080/ 1343943x.2015.1128101

Shimamura, S., Yoshioka, T., Yamamoto, R., Hiraga, S., Nakamura, T., Shimada, S., et al. (2014). Role of abscisic acid in flood-induced secondary aerenchyma formation in soybean (Glycine max) hypocotyls. Plant Prod. Sci. 17, 131-137. doi: $10.1626 /$ pps.17.131
Shiono, K., Ogawa, S., Yamazaki, S., Isoda, H., Fujimura, T., Nakazono, M., et al. (2011). Contrasting dynamics of radial O2-loss barrier induction and aerenchyma formation in rice roots of two lengths. Ann. Bot. 107, 89-99. doi: $10.1093 / \mathrm{aob} / \mathrm{mcq} 221$

Steffens, B., and Rasmussen, A. (2016). The physiology of adventitious roots. Plant Physiol. 170, 603-617. doi: 10.1104/pp.15.01360

Steffens, B., Geske, T., and Sauter, M. (2011). Aerenchyma formation in the rice stem and its promotion by H2O2. New Phytol. 190, 369-378. doi: 10.1111/j. 1469-8137.2010.03496.x

Sun, L., Ma, L., He, S., and Hao, F. (2018). AtrbohD functions downstream of ROP2 and positively regulates waterlogging response in Arabidopsis. Plant Signal. Behav. 13, e1513300. doi: 10.1080/15592324.2018.1513300

Tamang, B. G., Magliozzi, J. O., Maroof, M. S., and Fukao, T. (2014). Physiological and transcriptomic characterization of submergence and reoxygenation responses in soybean seedlings. Plant Cell Environ. 37, 23502365.

Tian, L., Li, J., Bi, W., Zuo, S., Li, L., Li, W., et al. (2019). Effects of waterlogging stress at different growth stages on the photosynthetic characteristics and grain yield of spring maize (Zea mays L.) Under field conditions. Agric. Water Manag. 218, 250-258. doi: 10.1016/j.agwat.2019.03.054

Tougou, M., Hashiguchi, A., Yukawa, K., Nanjo, Y., Hiraga, S., Nakamura, T., et al. (2012). Responses to flooding stress in soybean seedlings with the alcohol dehydrogenase transgene. Plant Biotechnol. 29, 301-305. doi: 10.5511/ plantbiotechnology.12.0301a

van Veen, H., Akman, M., Jamar, D. C., Vreugdenhil, D., Kooiker, M., van Tienderen, P., et al. (2014). Group VII E thylene response factor diversification and regulation in four species from flood-prone environments. Plant Cell Environ. 37, 2421-2432.

Vidoz, M. L., Loreti, E., Mensuali, A., Alpi, A., and Perata, P. (2010). Hormonal interplay during adventitious root formation in flooded tomato plants. Plant J. 63, 551-562. doi: 10.1111/j.1365-313x.2010.04262.x

Visser, E. J., and Voesenek, L. A. (2005). Acclimation to soil flooding-sensing and signal-transduction, in Root physiology: from gene to function. Plant Soil 274, 197-214. doi: 10.1007/1-4020-4099-7_10

Voesenek, L., Colmer, T., Pierik, R., Millenaar, F., and Peeters, A. (2006). How plants cope with complete submergence. New Phytol. 170, 213-226. doi: 10. 1111/j.1469-8137.2006.01692.x

Wang, C., Zhu, J., and Dai, S. (2016). Effects of chemical control and nutrient control on waterlogging of rapeseed in flower and fruit stage. Jiangsu Agric. Sci. 44, 136-138.

Wang, G., Fan, W., and Peng, F. (2015). Physiological responses of the young peach tree to water-logging and spraying SA at different timing. J. Fruit Sci. $32,872-878$.

Wang, J., Song, L., Gong, X., Xu, J., and Li, M. (2020). Functions of jasmonic acid in plant regulation and response to abiotic stress. Int. J. Mol. Sci. 21, 1446. doi: 10.3390/ijms21041446

Wang, X., Li, M., Jannasch, A. H., and Jiang, Y. (2020). Submergence stress alters fructan and hormone metabolism and gene expression in perennial ryegrass with contrasting growth habits. Environ. Exp. Bot. 179, 104202. doi: 10.1016/j. envexpbot.2020.104202

Wei, X., Xu, H., Rong, W., Ye, X., and Zhang, Z. (2019). Constitutive expression of a stabilized transcription factor group VII ethylene response factor enhances waterlogging tolerance in wheat without penalizing grain yield. Plant Cell Environ. 42, 1471-1485. doi: 10.1111/pce.13505

Winkel, A., Visser, E. J., Colmer, T. D., Brodersen, K. P., Voesenek, L. A., Sand-Jensen, K., et al. (2016). Leaf gas films, underwater photosynthesis and plant species distributions in a flood gradient. Plant Cell Environ. 39, 1537-1548. doi: 10.1111/pce.12717

Wu, H., Chen, H., Zhang, Y., Zhang, Y., Zhu, D., and Xiang, J. (2019). Effects of 1-aminocyclopropane-1-carboxylate and paclobutrazol on the endogenous hormones of two contrasting rice varieties under submergence stress. Plant Growth Regul. 87, 109-121. doi: 10.1007/s10725-018-0457-6

Wu, Y.-S., and Yang, C.-Y. (2016). Physiological responses and expression profile of NADPH oxidase in Rice (Oryza sativa) seedlings under different levels of submergence. Rice 9:2.

Xu, K., Xu, X., Fukao, T., Canlas, P., Maghirang-Rodriguez, R., Heuer, S., et al. (2006). Sub1A is an ethylene-response-factor-like gene that confers 
submergence tolerance to rice. Nature 442, 705-708. doi: 10.1038/nature 04920

Xu, X., Ji, J., Ma, X., Xu, Q., Qi, X., and Chen, X. (2016). Comparative proteomic analysis provides insight into the key proteins involved in cucumber (Cucumis sativus L.) adventitious root emergence under waterlogging stress. Front. Plant Sci. 7:1515. doi: 10.3389/fpls.2016.01515

Xu, X., Ji, J., Xu, Q., Qi, X., Weng, Y., and Chen, X. (2018). The major-effect quantitative trait locus Cs ARN 6.1 encodes an AAA ATP ase domaincontaining protein that is associated with waterlogging stress tolerance by promoting adventitious root formation. Plant J. 93, 917-930. doi: 10.1111/tpj. 13819

Xu, X., Wang, H., Qi, X., Xu, Q., and Chen, X. (2014). Waterlogging-induced increase in fermentation and related gene expression in the root of cucumber (Cucumis sativus L.). Sci. Hortic. 179, 388-395. doi: 10.1016/j.scienta.2014. 10.001

Yamauchi, T., Colmer, T. D., Pedersen, O., and Nakazono, M. (2018). Regulation of root traits for internal aeration and tolerance to soil waterloggingflooding stress. Plant Physiol. 176, 1118-1130. doi: 10.1104/pp.17. 01157

Yamauchi, T., Shimamura, S., Nakazono, M., and Mochizuki, T. (2013). Aerenchyma formation in crop species: a review. Field Crops Res. 152, 8-16. doi: 10.1016/j.fcr.2012.12.008

Yamauchi, T., Tanaka, A., Mori, H., Takamure, I., Kato, K., and Nakazono, M. (2016). Ethylene-dependent aerenchyma formation in adventitious roots is regulated differently in rice and maize. Plant Cell Environ. 39, 2145-2157. doi: $10.1111 /$ pce. 12766

Yamauchi, T., Tanaka, A., Tsutsumi, N., Inukai, Y., and Nakazono, M. (2020). A role for auxin in ethylene-dependent inducible aerenchyma formation in rice roots. Plants 9:610. doi: 10.3390/plants9050610

Yamauchi, T., Watanabe, K., Fukazawa, A., Mori, H., Abe, F., Kawaguchi, K., et al. (2014). Ethylene and reactive oxygen species are involved in root aerenchyma formation and adaptation of wheat seedlings to oxygen-deficient conditions. J. Exp. Bot. 65, 261-273. doi: 10.1093/jxb/er t371

Yamauchi, T., Yoshioka, M., Fukazawa, A., Mori, H., Nishizawa, N. K., Tsutsumi, N., et al. (2017). An NADPH oxidase RBOH functions in rice roots during lysigenous aerenchyma formation under oxygen-deficient conditions. Plant Cell 29, 775-790. doi: 10.1105/tpc.16.00976

Yan, K., Zhao, S., Cui, M., Han, G., and Wen, P. (2018). Vulnerability of photosynthesis and photosystem I in Jerusalem artichoke (Helianthus tuberosus L.) exposed to waterlogging. Plant Physiol. Biochem. 125, 239-246. doi: 10.1016/ j.plaphy.2018.02.017

Yang, C.-Y. (2014). Hydrogen peroxide controls transcriptional responses of ERF73/HRE1 and ADH1 via modulation of ethylene signaling during hypoxic stress. Planta 239, 877-885. doi: 10.1007/s00425-0132020-Z

Yang, C.-Y., and Hong, C.-P. (2015). The NADPH oxidase Rboh D is involved in primary hypoxia signalling and modulates expression of hypoxia-inducible genes under hypoxic stress. Environ. Exp. Bot. 115, 63-72. doi: 10.1016/j. envexpbot.2015.02.008

Yang, S.-H., and Choi, D. (2006). Characterization of genes encoding ABA 8'hydroxylase in ethylene-induced stem growth of deepwater rice (Oryza sativa L.). Biochem. Biophys. Res. Commun. 350, 685-690. doi: 10.1016/j.bbrc.2006. 09.098

Yin, D., Sun, D., Han, Z., Ni, D., Norris, A., and Jiang, C.-Z. (2019). PhERF2, an ethylene-responsive element binding factor, plays an essential role in waterlogging tolerance of Petunia. Hortic. Res. 6, 1-11.
Yu, F., Liang, K., Fang, T., Zhao, H., Han, X., Cai, M., et al. (2019). A group VII ethylene response factor gene, $\mathrm{ZmEREB} 180$, coordinates waterlogging tolerance in maize seedlings. Plant Biotechnol. J. 17, 2286-2298. doi: 10.1111/pbi.13140

Zabalza, A., Van Dongen, J. T., Froehlich, A., Oliver, S. N., Faix, B., Gupta, K. J., et al. (2009). Regulation of respiration and fermentation to control the plant internal oxygen concentration. Plant Physiol. 149, 1087-1098. doi: 10.1104/pp. 108.129288

Zhang, G., Tanakamaru, K., Abe, J., and Morita, S. (2007). Influence of waterlogging on some anti-oxidative enzymatic activities of two barley genotypes differing in anoxia tolerance. Acta Physiol. Plant. 29, 171-176. doi: 10.1007/s11738-0060022-1

Zhang, J.-Y., Huang, S.-N., Wang, G., Xuan, J.-P., and Guo, Z.-R. (2016). Overexpression of Actinidia deliciosa pyruvate decarboxylase 1 gene enhances waterlogging stress in transgenic Arabidopsis thaliana. Plant Physiol. Biochem. 106, 244-252. doi: 10.1016/j.plaphy.2016.05.009

Zhang, P., Lyu, D., Jia, L., He, J., and Qin, S. (2017). Physiological and de novo transcriptome analysis of the fermentation mechanism of Cerasus sachalinensis roots in response to short-term waterlogging. BMC Genomics 18:649. doi: 10. 1186/s12864-017-4055-1

Zhang, Q., Liu, X., Zhang, Z., Liu, N., Li, D., and Hu, L. (2019). Melatonin improved waterlogging tolerance in alfalfa (Medicago sativa) by reprogramming polyamine and ethylene metabolism. Front. Plant Sci. 10:44. doi: 10.3389/fpls. 2019.00044

Zhang, R., Zhou, Y., Yue, Z., Chen, X., Cao, X., Xu, X., et al. (2019). Changes in photosynthesis, chloroplast ultrastructure, and antioxidant metabolism in leaves of sorghum under waterlogging stress. Photosynthetica 57, 1076-1083. doi: $10.32615 /$ ps.2019.124

Zhang, Y., Chen, Y., Lu, H., Kong, X., Dai, J., Li, Z., et al. (2016). Growth, lint yield and changes in physiological attributes of cotton under temporal waterlogging. Field Crops Res. 194, 83-93. doi: 10.1016/j.fcr.2016.05.006

Zhang, Y., Song, X., Yang, G., Li, Z., Lu, H., Kong, X., et al. (2015). Physiological and molecular adjustment of cotton to waterlogging at peak-flowering in relation to growth and yield. Field Crops Res. 179, 164-172. doi: 10.1016/j.fcr.2015.05.001

Zheng, X., Zhou, J., Tan, D.-X., Wang, N., Wang, L., Shan, D., et al. (2017). Melatonin improves waterlogging tolerance of Malus baccata (Linn.) Borkh. seedlings by maintaining aerobic respiration, photosynthesis and ROS migration. Front. Plant Sci. 8:483. doi: 10.3389/fpls.2017.00483

Zhou, W., Chen, F., Meng, Y., Chandrasekaran, U., Luo, X., Yang, W., et al. (2020). Plant waterlogging/flooding stress responses: from seed germination to maturation. Plant Physiol. Biochem. 148, 228-236. doi: 10.1016/j.plaphy.2020. 01.020

Zhou, Z. S., Guo, K., Elbaz, A. A., and Yang, Z. M. (2009). Salicylic acid alleviates mercury toxicity by preventing oxidative stress in roots of Medicago sativa. Environ. Exp. Bot. 65, 27-34. doi: 10.1016/j.envexpbot.2008.06.001

Zhu, J.-K. (2016). Abiotic stress signaling and responses in plants. Cell 167, 313-324. doi: 10.1016/j.cell.2016.08.029

Conflict of Interest: The authors declare that the research was conducted in the absence of any commercial or financial relationships that could be construed as a potential conflict of interest.

Copyright (c) 2021 Pan, Sharif, Xu and Chen. This is an open-access article distributed under the terms of the Creative Commons Attribution License (CC BY). The use, distribution or reproduction in other forums is permitted, provided the original author(s) and the copyright owner(s) are credited and that the original publication in this journal is cited, in accordance with accepted academic practice. No use, distribution or reproduction is permitted which does not comply with these terms. 